\title{
Cross-listing and pricing efficiency: The informational and anchoring role played by the reference price ${ }^{\sqrt{2}}$
}

\author{
Eric C. Chang ${ }^{\mathrm{a}, *}$, Yan Luo ${ }^{\mathrm{b}}$, Jinjuan Ren ${ }^{\mathrm{c}}$ \\ ${ }^{a}$ Faculty of Business and Economics, The University of Hong Kong, Pokfulam Road, Hong Kong. \\ ${ }^{b}$ School of Management, Fudan University, No. 670 Guoshun Road, Shanghai, China 200433 \\ ${ }^{c}$ Faculty of Business Administration, University of Macau, Av. Padre Tomás Pereira, Taipa, Macau, China
}

This version: December 12, 2012

\begin{abstract}
When a firm cross-lists its shares in segmented markets, the price of the first issued share, as a reference, plays both an informational and anchoring role in pricing the second issued share. We develop a model illustrating the dual-role. Empirically, we examine a group of Chinese firms that first issue foreign shares and then domestic A-shares, for which the anchoring effect adds to the Ashare underpricing. Consistent with the model predictions, we find that the A-share underpricing is positively related to the difference in costs of capital in the two segmented markets, and that this positive association is weaker when participants are less likely to resort to the anchoring heuristic and when the A-share valuation involves less uncertainty.
\end{abstract}

Keywords: cross-listing; segmented market; anchoring; IPO underpricing JEL classification: G12; G14; G15; G24

\footnotetext{
${ }^{2}$ We acknowledge the financial support from Hong Kong Research Grant Council (RGC) General Research Fund (HKU741709H), Shanghai Pujiang Talents Program (No. KBH1019670), and High-End Academic Research Project of Financial Research Center of Fudan University. We thank an anonymous referee for his/her constructive comments and suggestions. We benefit a lot from the comments and suggestions from Hung Xuan Do, Zhigang Li, Hung Wan Kot, Eng-Tuck Cheah, Michael Halling, Joseph Cheng, Konan Chan, Xianming Zhou, seminar participants in seminars organized by the University of Hong Kong, Hong Kong Baptist University, and University of Macau, and participants at the 2011 24th Australasian Finance and Banking Conference in Sydney, Australia, the 2009 European Financial Management Association (EFMA) conference in Milan, Italy, the 2009 China International Conference in Finance (CICF) in Guangzhou, China, and the 2009 Financial Management Association (FMA) conference in Reno, Nevada.

${ }^{*}$ Corresponding author. Tel.: +852 2219 4567; fax: +852 25485471.

Email addresses: ecchang@business.hku.hk (Eric C. Chang), luoyan@fudan.edu.cn (Yan Luo), jinjuanren@umac.mo (Jinjuan Ren)
} 


\section{Introduction}

When a firm issues stocks to the public for the first time, this offering is an initial public offering (IPO). For a firm with publicly issued shares, its follow-on issuance is a seasoned equity offering (SEO). How about a firm that cross-lists its shares in two markets? Is the second listing an IPO, as this firm is new in the second market, or an SEO, as the firm has already listed its shares in the first market? In this study, we argue that the second offering is not an IPO, as the price history of the first issued share arguably provides ample information in pricing the second issued share. Neither is it an SEO, as the price of the first issued share is not a ready reference for the second issued share across boarders and plays an anchoring role. In a nutshell, we propose that in pricing the second issued share, the price of the first issued share, as a reference, serves both a beneficial informational role and a possibly harmful anchoring role.

Prior literature shows that for a security traded in multiple markets, the price from one market, as an important and conspicuous reference, helps to price the same security traded in other markets (Eun and Sabherwal, 2003). However, the referred price may not be a perfect reference due to market segmentation. Cross-listing normally involves cross-border listings, and the home market is often mildly or even severely segmented from the foreign market (Foerster and Karolyi, 1999; Chan et al., 2008), resulting in different rates of returns required by respective investors. Therefore, even for the same security issued by the same firm, prices across borders are not directly comparable. Consequently, the price from one market could be a biased and noisy reference for the price of shares issued in another market. Behavioral biases such as the anchoring heuristic (Tversky and Kahneman, 1974) might take effect in this occasion. We argue that for a firm that cross-lists its shares in two markets, in pricing the second issued share, market participants have a tendency to pay too much attention to the price of the first issued share at its face value and adjust insufficiently for the difference in the required rates of returns in the two markets. As a result, the offer price of the second issued share is biased toward the price of the first issued share.

We formalize the foregoing reasoning and develop a general model to describe the beneficial informational role and the possibly harmful anchoring role played by the reference price. Many 
studies have shown that the offer price in a typical IPO tends to be downward biased, and that IPOs on average are underpriced (e.g. Loughran et al., 1994). This downward-biased offer price is the prior. Then, we model the reference price revealed in another segmented market as a noisy signal, which is biased by the degree of valuation difference between the two classes of shares. In a rational Bayesian framework, investors can see through market segmentation and automatically adjust for the bias in the signal. In this situation, the information contained in the reference helps to reduce the underpricing. If market participants suffer from the anchoring bias, however, they tend to rely on the biased signal at its face value and fail to adjust sufficiently for the valuation difference. Consequently, the offer price is biased and the degree of underpricing is associated with the valuation difference. Specifically, if the reference price is consistently downward biased, the offer price is also downward biased due to the anchoring effect, resulting in greater underpricing. Conversely, if the reference price is consistently upward biased, the anchoring effect produces upward bias in the offer price, mitigating the degree of underpricing.

We utilize the IPO data of cross-listed Chinese firms to test the dual-role model empirically. As of December 31, 2010, 80 Chinese firms at some point first issued foreign shares (either on the Hong Kong exchange as H-shares or on the Chinese B-share market) and then issued Chinese A-shares. At the A-share issuance, the trading price of the corresponding foreign share is available as a reference and arguably plays a dual-role. This data set is appropriate for testing the dualrole model for at least four reasons. First, the tight control on capital accounts by the Chinese government exacerbates the segmentation between the Chinese domestic market and the foreign market, resulting in substantial difference between the two markets. Second, domestic A-share investors require a lower rate of return than foreign investors do (Fernald and Rogers, 2002, among others). This translates to higher asset valuation in the A-share market than in the foreign market. Thus, the foreign share price, when given too much weight, serves as a downside anchor that biases the A-share offer price downward. For this specific sample, the anchoring effect is harmful and results in greater underpricing, making the A-share first-day return an ideal proxy for the anchoring bias. Third, the primary market arguably involves higher valuation uncertainty than the 
secondary market, which further highlights the importance of both the informational and anchoring role played by the reference price. Finally, the Chinese securities market is still underdeveloped, and Chinese investors are relatively unsophisticated and more vulnerable to cognitive biases. The IPOs of Chinese cross-listed firms provide us with an ideal opportunity to examine the dual-role model.

In the empirical tests, we use the offer price-to-earnings (PE) ratio to proxy for the anchored estimate of the A-share valuation level, and use the aftermarket PE observed one month after the Ashare listing in the A-share market to proxy for the rational estimate. The foreign share PE ratio is used to proxy for the reference valuation level. The valuation difference is proxied by the difference in costs of equity capital, measured by the one-year buy-and-hold returns on respective foreignand A-shares. Cross-sectionally, we find two pieces of evidence supporting the informational role played by the reference price. First, both the offer PE ratio and the aftermarket PE ratio are significantly positively related to the foreign share PE. Second, we discover a significant relation between the aftermarket PE and the A-share buy-and-hold returns. These two pieces of evidence suggest that the aftermarket PE ratio incorporates information concerning firm-level cash flows revealed by the foreign PE ratio, as well as information on the cost of capital in the A-share market. In contrast, we fail to find a significant relation between the offer PE ratio and the A-share buy-and-hold returns. This evidence suggests that in determining the A-share offer price, decision makers incline to refer to the foreign share valuation only and fail to adjust the estimate sufficiently for the valuation difference, consistent with the anchoring hypothesis.

We then examine the relation between the A-share underpricing and the valuation difference. The A-share underpricing is proxied by the first-day return upon the A-share listing. We find that after controlling for the adjustment made in the offering stage, the first-day return is still positively associated with the valuation difference, supporting the anchoring and insufficient adjustment argument. Specifically, the first-day return has a significantly negative association with the A-share buy-and-hold returns. It suggests that market participants tend to under-react to the variations in the A-share's cost of capital, but not to the foreign share's cost of capital, lending further support 
to the anchoring argument.

Furthermore, consistent with the model predictions, we find that the positive association between the A-share underpricing and the valuation difference is weaker when market participants are less likely to suffer from the anchoring bias, such as when the scale of the share issuance is larger, when the state ownership is diluted to a greater extent after the new share issuance, or when the flotation costs are lower. Besides, when the valuation uncertainty of A-shares is higher, as indicated by a higher first-day turnover ratio, the positive association between the underpricing and buy-and-hold returns is stronger. These results remain robust after we control for various determinants of underpricing and in different model specifications.

Our study contributes to the international finance literature in that we are the first to advocate the anchoring role played by the reference price in cross-listing. The proposed model and related analysis are applicable to foreign firms that use domestic share price as a reference in pricing their ADRs issued in the United States, or use the price of U.S. ADRs as a reference in pricing domestic shares. We remind market participants that the reference price also plays an anchoring role, which might work against its beneficial informational role and reduce pricing efficiency.

Besides, we conjecture that the anchoring bias in the financial market possibly influences managerial decisions on the listing sequence. An optimal strategy is to first issue shares in a market with a higher valuation level, and then issue shares in a market with a lower valuation level. By taking advantage of investors' anchoring bias, the issuer could boost its offer price and reduce underpricing in the second issuance. As the average valuation level is higher in the A-share market than in the H-share market, the first-A-then-H listing sequence could work to reduce the $\mathrm{H}$-share underpricing, due to the anchoring propensity of investors in the H-share market. For instance, Minsheng Bank listed its A-shares in December 2000 and H-shares in November 2009. The firstday return on its $\mathrm{H}$-share listing was $-11.65 \%$, and our anchoring argument could at least partially explain this phenomenon.

Our study also adds to the behavioral finance studies on the anchoring effect (Shafir et al., 1997; George and Hwang, 2004; Campbell and Sharpe, 2009; Cen et al., 2012; Chang et al., 2011, 
among others) by providing an additional piece of evidence from the primary market. We develop a model to describe one possible channel through which the anchoring bias might exert its influence. A generalization of this framework has the potential to explain the anchoring effect in other scenarios as well.

This study contributes to the extensive IPO literature. We take a behavioral standpoint and document an additional factor that may affect the degree of underpricing. Our anchoring argument is compatible with those of Loughran and Ritter (2002) and Krigman et al. (1999). Purnanandam and Swaminathan (2004) emphasize that the valuation levels of comparable firms are reasonable benchmarks for pricing new shares. This study, however, specifically investigates market participants' "misuse" of references resulting from their failure to adjust the estimate sufficiently for the underlying differences.

Finally, this study has important practical implications for Chinese economic reform. First, although Chinese financial market has experienced a rapid expansion, it is still relatively underdeveloped. Many investors, issuers, and even regulators fail to understand the barriers between domestic and foreign markets, and thus tend to suffer from strong anchoring bias. Our study could help these market participants to understand market segmentation better and improve pricing efficiency. Second, our study has general applications beyond the A-H cross-listing. Many foreign firms (e.g., HSBC) and giant Chinese firms with red-chip shares (e.g. China Mobile, China Offshore Oil, and China Netcom) have expressed strong interests in issuing A-shares. Although these foreign entities are currently proscribed from issuing shares in the mainland market under Chinese Security Law and listing rules, we believe that changes in the regulation could be expected in the foreseeable future to pave the way for the development of Shanghai International Board. Our anchoring argument is applicable in such a broader cross-listing context. Third, policy-makers have been discussing the application of a so-called "arbitrage mechanism" to eliminate the price difference between A-shares and their corresponding H-shares. However, no such a mechanism can effectively "arbitrage" away the difference if the Chinese financial market is not fully liberalized. Fourth, Chinese firms such as the Industrial and Commercial Bank of China (ICBC) and China 
CITIC bank implemented an "A+H" IPO mechanism by issuing A- and H-shares simultaneously at the same price in 2006 and 2007, respectively. We argue that such a "A+H" design is inferior, as issuers could have raised more funds by offering different prices in the two markets. Some other firms issued A- and H-share in a synchronized issuance (e.g., China Southern Locomotive, Metallurgical Corporation of China, and New China Life Insurance in 2007, 2009 and 2011, respectively), in which the offer price of the A-share is designed to be no higher than that of the corresponding H-share. Such a design dampens the A-share pricing efficiency to a greater extent, as the lower cost of capital in the A-share market suggests that the A-shares should be traded at a premium relative to their H-share counterparts.

The rest of this article goes as follows. Section 2 reviews related streams of literature. Section 3 develops a theoretical model and testable hypotheses. Section 4 introduces the data sources and presents our baseline empirical results, and Section 5 shows the results of robustness tests. Section 6 concludes.

\section{Literature review}

\subsection{Cross-listings}

The global capital market has experienced accelerating cross-border capital flows over the past twenty years. At the same time, cross-listing has become an important financing strategy for companies. Firms that list shares on multiple exchanges gain access to capital sources abroad with lower costs of capital (Errunza and Miller, 2000; Foerster and Karolyi, 1999). Existing studies show that the benefits obtained from cross-listing usually outweigh the additional costs incurred.

Fernandes and Ferreira (2008) report a sample of 2,955 foreign firms listed in the U.S. market by 2003 via ordinary listings, ADRs, OTC listings, or Rule 144a private placements. If a firm issues domestic shares before issuing shares in the U.S. market, its U.S. listing resembles a seasoned equity offering (SEO). When a firm sequentially issues shares in multiple markets, existing shares undoubtedly become references for pricing the new shares. 


\subsection{The informational role by the reference price}

Hayek (1945) states that "we must look at the price system as such a mechanism for communicating information if we want to understand its real function ... by a kind of symbol, only the most essential information is passed on..." (p. 527). This proposition suggests that the price (symbol) is a concise and useful reference. This intuitive argument is widely supported in the literature. For example, Eun and Sabherwal (2003) find that for a firm cross-listed on the U.S. and Canadian exchanges, its stock prices in two markets mutual-adjust to each other, indicating that information flows across borders. The evidence suggests that for a cross-listed firm, the share price in one market, as a concise and useful reference that conveys important information, helps to promote the pricing efficiency in another market.

\subsection{Market segmentation}

Cross-listing normally involves cross-border listings, and the home market is often mildly or even severely segmented from the foreign market. For cross-listed securities, although the foreign and domestic shares are entitled to identical cash flow rights and voting rights, there are still substantial differences between them. The legal environment, government regulations, and the degree of financial market development may differ at the institutional level. Besides, there are differences in preferences, risk attitudes, sentiment, and degrees of sophistication at the individual investor's level. As a result, shares with identical fundamental business and financial risks, but listed in two different markets, may have different required rates of returns, and thus differ in their costs of capital. In the remainder of this article, we use the cost of capital and the required rate of return interchangeably.

Chinese domestic investors require lower rates of returns than foreign investors as a result of the severe market segmentation (Fernald and Rogers, 2002). The Chinese B-share market and the Hong Kong market are integrated with the global market and have few barriers to the capital flows. ${ }^{1}$

\footnotetext{
${ }^{1}$ The B-share market differs from the H-share market in several aspects. First, the B-share market was established along with the A-share market in the early 1990s, and it is regulated and operated by Chinese government agencies. In comparison, the Hong Kong market is independent from the Chinese government. Second, the B-share market is
} 
The cost of capital of foreign shares is thus determined by the risk and time-value compensation required by average international investors. In comparison, the Chinese securities market is only semi-liberalized, and the most pronounced barriers are the tight control on inward and outward capital accounts. The excessive demand for securities relative to the limited supply in the Chinese stock market pushes domestic Chinese investors to require relatively lower returns on A-share investments. $^{2}$

In addition to market segmentation, existing literature shows that the exposure to different market factors (Wang and Jiang, 2004), higher information asymmetry faced by foreign investors (Chan et al., 2008), weaker corporate governance in China (Cai et al., 2011), RMB appreciation and the sentiment (Arquette et al., 2008) also contribute to the lower costs of capital required by Chinese domestic investors compared to foreign investors and lead to the A-share premium relative to H-share. However, the A-H premium drops substantially in recent years, and from 2010 to 2012, A-shares were sometimes traded at a discount to $\mathrm{H}$-shares at the aggregate level. Echoing Cai et al. (2011), we argue that Chinese market liberalization helps to reduce the H-share discount, but the excess demand for securities in the Chinese market will result in the foreign share discount in the

small with only 114 shares thinly traded, and stock prices are often volatile. In contrast, 1,413 firms are listed on the Hong Kong Security Exchange (Main Board and Growth Enterprise Market) by December 2010, and among them 592 firms are from China (including $163 \mathrm{H}$-shares, 102 red-chips, and 327 non-H-Share mainland private enterprises), contributing to $56.6 \%$ of the capitalization of Hong Kong securities market. (Sources: Hong Kong Exchanges and Clearing Limited.) H-shares are issued by companies incorporated in mainland China but are traded on the Hong Kong Stock Exchange. In comparison, Red-chip stocks are issued by companies that have mainland China background and are incorporated outside mainland China and listed in Hong Kong. Finally, since February 19, 2001 Chinese domestic investors have been able to trade B-shares as well, although the A- and B-shares of the same firm are still not interchangeable.

${ }^{2}$ In Chinese A-share market, since the domestic capital cannot freely flow into foreign financial markets at a reasonably low cost, domestic investors cannot conveniently seek better investment opportunities in overseas markets. Chinese investors thus have very limited investment opportunities and the A-share securities market is one of the few possibilities, especially when the government suppresses the deposit interest rate to a quite low level (sometimes even lower than the inflation rate). In the meantime, as international investors are seeking global risk diversification opportunities, a total amount of 24.5 billion U.S. dollar foreign capital has flowed into the A-share market through Qualified Foreign Institutional Investors (QFII) mechanism (March 3, 2012, reported by State Administration of Foreign Exchange, China. http://www.safe.gov.cn). These factors contribute to strong demand for securities in the Chinese market, while the supply is rather limited. In the 1990s, limited issuance quotas restricted the scale of the stock market, and the procedures for obtaining the listing approval or to verify the eligibility for qualification were complex and time-consuming. No foreign firms were able to list shares in Chinese exchanges as of March 2012, and some Chinese firms listed shares abroad, further limiting the supply of securities. The Qualified Domestic Institutional Investors (QDII) only partially helps to solve the over-demand problem. We examine the impact of QDII in details in Section 5.4 . 
long run. As it is difficult to find an uncontroversial proxy for firm's cost of equity capital, we do not select risk factors or estimate factor loadings. Instead, we use the terminology "difference in costs of capital" to refer to the overall pricing difference between cross-listed shares, which have exactly the same fundamentals.

The market-average PE ratio represents the valuation level in each market. As an illustration, we calculate the median PE ratio based on all stocks listed on the A-share, B-share, and Hong Kong markets, respectively. Figure 1 plots the median PE ratio of each market over time. The median PE ratio in the A-share market is much higher than that in the B-share or Hong Kong market during most of the time. On the condition that the average fundamentals of listed firms in respective markets are largely the same, the higher PE ratio in the A-share market supports our argument that investors in the A-share market require lower rates of returns than foreign investors.

\subsection{The anchoring bias}

In pricing assets across segmented markets, the anchoring effect is a behavioral bias that may possibly reduce the pricing efficiency. Tversky and Kahneman (1974) define anchoring as follows: "in many situations, people make estimates by starting from an initial value that is adjusted to yield the final answer ... adjustments are typically insufficient. That is, different starting points yield different estimates, which are biased toward the initial values. We call this phenomenon anchoring." (p. 1128) Tversky and Kahneman (1974) assert that the more ambiguous the value of a commodity, the more likely that the anchoring bias will take effect in the determination of its price. Chapman and Johnson (2002) suggest that the monetary incentives help to reduce the anchoring bias.

Past studies examine the anchoring effect in various contexts. Shafir et al. (1997) postulate that anchoring on the nominal evaluation gives rise to the money illusion. Campbell and Sharpe (2009) find that consensus forecasts of monthly economic releases are biased toward the values of previous months' data releases, and market participants anticipate that anchoring bias. Cen et al. (2012) find that analyst forecasts are cross-sectionally anchored to the industry median, and such forecast errors predict stock returns. George and Hwang (2004) argue that traders might use the 
52-week high as an "anchor" when assessing the stock price change implied by new information. Chang et al. (2011) use the anchoring effect to explain the ex-day abnormal returns for stock distributions. Our study provides an additional piece of evidence of anchoring in the cross-listing context. Specifically, we are the first to propose a possible channel through which the anchoring bias takes effect: as the signal is consistently biased, putting too much weight on the signal and thus failing to adjust the estimate sufficiently for the underlying difference effectively build the anchoring bias into the estimate. Our model is applicable to other anchoring-related scenarios.

\subsection{IPO underpricing}

Our study contributes to the extensive IPO literature by investigating the influence of the anchoring bias. IPO Underpricing is a persistent worldwide phenomenon and attracts attention from both academia and practitioners. The updated statistics in Loughran et al. (1994) show an average $18 \%$ of IPO underpricing in the U.S. market from 1960 to 2006 . The degree of underpricing varies widely across the global equity markets, and the Chinese stock market is among one of those with the highest levels of IPO underpricing. Chen et al. (2008), among others, report an average underpricing of $165 \%$ for 1,394 IPOs in China between 1990 and 2005.

Researchers have investigated the origin of IPO underpricing extensively over the past decades. Many existing studies offer explanations based on incomplete or asymmetric information arguments, while some others seek alternative explanations from behavioral perspectives (e.g., Loughran and Ritter, 2002). These theories face great challenges in explaining the tremendous profits in the Chinese primary market. Tian (2011) argues that the government intervenes the IPO pricing process through setting a pricing cap and controls the IPO supply, contributing to extremely high underpricing. Chen et al. (2008) maintain that the Chinese bureaus deliberately underprice the IPOs of stateowned enterprises to obtain a higher probability of being promoted. Fan et al. (2007) argue that non-politically-connected CEOs underprice shares to signal their credible intention of relinquishing the control of their firms. In this study, we propose the anchoring effect as an alternative explanation applicable to cross-listed firms. 


\section{Model and hypotheses}

In this section, we develop a model to illustrate the informational and anchoring role played by the reference price.

\subsection{The informational role}

In a general case, a security's true value $\theta$ is assumed to follow a normal distribution: $\theta \sim$ $\mathcal{N}\left(\bar{\theta}, \sigma_{\theta}^{2}\right)$. A public noisy signal $s$ is then observed: $s=\theta+\epsilon$, where $\epsilon$ is a white noise: $\epsilon \sim$ $\mathcal{N}\left(0, \sigma_{\epsilon}^{2}\right)$ and $\epsilon$ is orthogonal to $\theta$. The conditional expectation of $\theta$ by rational participants is denoted as $E_{R}$. According to the orthogonality principle,

$E_{R}=\frac{\sigma_{\epsilon}^{2}}{\sigma_{\theta}^{2}+\sigma_{\epsilon}^{2}} \bar{\theta}+\frac{\sigma_{\theta}^{2}}{\sigma_{\theta}^{2}+\sigma_{\epsilon}^{2}} s$

This conditional estimate $E_{R}$ is a weighted average of the prior $\bar{\theta}$ and the signal $s$. As the weights fall within [0,1], $E_{R}$ lies between $\bar{\theta}$ and $s$ inclusive. If $s>\bar{\theta}$, the conditional estimate $E_{R}$ is higher than the prior $\bar{\theta}$ and $s$ is thus called a positive signal. Conversely, if $s<\bar{\theta}, E_{R}$ is lower than $\bar{\theta}$ and $s$ is called a negative signal.

\subsubsection{IPO: A wrong prior}

In pricing the second issued share in cross-listing, we assume that market participants first collect all available domestic information and form a prior $\bar{\theta}^{\prime}$, and then observe the signal $s$ that is the price of the first issued share in another market. IPO underpricing literature suggests that the offer price $\bar{\theta}^{\prime}$ tends to be lower than the true value $\bar{\theta}$. The initial underpricing is

$\theta-\bar{\theta}^{\prime} \sim \mathcal{N}\left(\bar{\theta}-\bar{\theta}^{\prime}, \sigma_{\theta}^{2}\right)$

Participants then observe the reference price $s$. Given the wrong prior $\bar{\theta}^{\prime}$ and the informative signal $s$, the rational conditional estimate is

$E_{R}=\frac{\sigma_{\epsilon}^{2}}{\sigma_{\theta}^{2}+\sigma_{\epsilon}^{2}} \bar{\theta}^{\prime}+\frac{\sigma_{\theta}^{2}}{\sigma_{\theta}^{2}+\sigma_{\epsilon}^{2}} s$, 
where $E_{R}$ is a weighted average of the signal $s$ and the wrong prior $\bar{\theta}^{\prime}$. Although the belief in the mean prior is wrong, people are rational in processing the signal $s$ to form the conditional estimate.

\subsubsection{A consistently biased signal}

The signal $s$ needs more elaboration. In the empirical tests, we utilize a special sample of cross-listed Chinese firms that first issue foreign B- or H-shares, and then domestic A-shares. In pricing the second issued A-shares, the price of the first issued foreign share is a natural reference. However, it is common knowledge that the A-share tends to be traded at a premium relative to its corresponding B-/H-share price. Consequently, the observed foreign share price at face value is a consistently downward-biased signal. This reference price at face value is

$s^{\prime}=s-c=\theta-c+\epsilon$,

where $c$ is a constant, representing the valuation difference between shares cross-listed in two segmented markets. In the case of a first-foreign-then-A listing sequence, in pricing the second issued A-share, $c>0$.

The rational estimate of the second issued share is accordingly

$E_{R}=\frac{\sigma_{\epsilon}^{2}}{\sigma_{\theta}^{2}+\sigma_{\epsilon}^{2}} \bar{\theta}^{\prime}+\frac{\sigma_{\theta}^{2}}{\sigma_{\theta}^{2}+\sigma_{\epsilon}^{2}}\left(s^{\prime}+c\right)=\frac{\sigma_{\epsilon}^{2}}{\sigma_{\theta}^{2}+\sigma_{\epsilon}^{2}} \bar{\theta}^{\prime}+\frac{\sigma_{\theta}^{2}}{\sigma_{\theta}^{2}+\sigma_{\epsilon}^{2}} s$.

We find that $c$, the bias in the prior, is automatically corrected in the Bayesian framework such that Eq. (5) has the same presentation as Eq. (3). The true information contained in the reference is actually $s=s^{\prime}+c$, not its face value $s^{\prime}$.

After observing the reference price $s^{\prime}$, participants update the prior $\bar{\theta}^{\prime}$ to $E_{R}$, and the conditional underpricing is accordingly

$\theta-E_{R}=\frac{\sigma_{\epsilon}^{2}}{\sigma_{\theta}^{2}+\sigma_{\epsilon}^{2}}\left(\theta-\bar{\theta}^{\prime}\right)-\frac{\sigma_{\theta}^{2}}{\sigma_{\theta}^{2}+\sigma_{\epsilon}^{2}} \epsilon$ 
The expected underpricing is

$E\left[\theta-E_{R}\right]=\frac{\sigma_{\epsilon}^{2}}{\sigma_{\theta}^{2}+\sigma_{\epsilon}^{2}}\left(\bar{\theta}-\bar{\theta}^{\prime}\right)<=E\left[\theta-\bar{\theta}^{\prime}\right]=\bar{\theta}-\bar{\theta}^{\prime}$

The variance of this underpricing is

$\operatorname{Var}\left[\theta-E_{R}\right]=\frac{\sigma_{\epsilon}^{2}}{\sigma_{\theta}^{2}+\sigma_{\epsilon}^{2}} \sigma_{\theta}^{2}<=\operatorname{Var}\left[\theta-\bar{\theta}^{\prime}\right]=\sigma_{\theta}^{2}$

Eq. (7) and (8) reveal the informational role played by the reference price. After participants observe the reference $s^{\prime}$ and correctly update the estimation, the conditional underpricing is on average reduced with a smaller variance. The average conditional underpricing is only a fraction of the average unconditional underpricing, and the variance of the conditional underpricing is the same fraction of the variance of unconditional underpricing. This fraction $\sigma_{\epsilon}^{2} /\left(\sigma_{\theta}^{2}+\sigma_{\epsilon}^{2}\right)$ is determined by the valuation uncertainty of the second-issued share itself and by the precision of the signal $s^{\prime}$. As $\theta$ is more uncertain (higher $\sigma_{\theta}^{2}$ ) and/or the signal $s^{\prime}$ is more precise (lower $\sigma_{\epsilon}^{2}$ ), the fraction is smaller, indicating a greater benefit brought by the signal $s^{\prime}$. This model prediction is consistent with the intuition that ignoring the information cost, information production is beneficial in reducing the expected IPO underpricing.

\subsection{The anchoring role}

We rewrite Eq. (3) or (5) as

$E_{R}=s-\frac{\sigma_{\epsilon}^{2}}{\sigma_{\theta}^{2}+\sigma_{\epsilon}^{2}}\left(s-\bar{\theta}^{\prime}\right)$.

The above equation shows an adjustment framework frequently used in reality. As predicted by the anchoring-and-adjustment heuristic, people tend to choose a starting point and then make directional adjustment. Rational participants will choose the true signal $s$ as the starting point and then make adjustment. The adjustment is downward if $s>\bar{\theta}^{\prime}$ and upward if $s<\bar{\theta}^{\prime}$. The magnitude of adjustment is the proportion $\sigma_{\epsilon}^{2} /\left(\sigma_{\theta}^{2}+\sigma_{\epsilon}^{2}\right)$ of the distance $\left|s-\bar{\theta}^{\prime}\right|$. Note that rational participants start with the true signal $s=s^{\prime}+c$, not the face value $s^{\prime}$. In addition, the direction and magnitude 
of the adjustment is determined by the comparing $s$ (not $s^{\prime}$ ) with $\bar{\theta}^{\prime}$.

\subsubsection{Anchoring: Insufficient adjustment}

Predicted by the anchoring-and-adjustment heuristic, participants incline to choose an evident/seemingly important value as the starting point, which tends to be an anchor, and then adjust the estimate insufficiently toward the final estimate. As the true signal $s$ is unobservable and hard to obtain, we assume that participants choose the face value $s^{\prime}$ as the starting point. Participants thus incline to adopt the following pricing strategy

$E_{R}=s^{\prime}-\frac{\sigma_{\epsilon}^{2}}{\sigma_{\theta}^{2}+\sigma_{\epsilon}^{2}}\left(s^{\prime}-\bar{\theta}^{\prime}\right)+\frac{\sigma_{\theta}^{2}}{\sigma_{\theta}^{2}+\sigma_{\epsilon}^{2}} c$

Eq. (10) is equivalent to Eq. (9). It shows that if participants start with the face value $s^{\prime}$ instead of the true value $s$, they should adjust for an additional component of $\sigma_{\theta}^{2} /\left(\sigma_{\theta}^{2}+\sigma_{\epsilon}^{2}\right) c$ to get the rational estimate.

Predicted by the anchoring heuristic, however, the adjustment toward the final estimate is usually insufficient. There are alternative ways to model this insufficient adjustment: participants may underestimate the fraction $\sigma_{\epsilon}^{2} /\left(\sigma_{\theta}^{2}+\sigma_{\epsilon}^{2}\right)$, the distance $s^{\prime}-\bar{\theta}^{\prime}$, or/and the bias $c$. Specific to the cross-listing scenario, we simply assume that participants underestimate $c$. We use a coefficient

$\gamma \in[0,1]$ to measure the anchoring propensity, with a lower $\gamma$ representing stronger anchoring propensity. The anchored estimate, denoted as $E_{A}$, is

$E_{A}=s^{\prime}-\frac{\sigma_{\epsilon}^{2}}{\sigma_{\theta}^{2}+\sigma_{\epsilon}^{2}}\left(s^{\prime}-\bar{\theta}^{\prime}\right)+\frac{\sigma_{\theta}^{2}}{\sigma_{\theta}^{2}+\sigma_{\epsilon}^{2}} \gamma c=\frac{\sigma_{\epsilon}^{2}}{\sigma_{\theta}^{2}+\sigma_{\epsilon}^{2}} \bar{\theta}^{\prime}+\frac{\sigma_{\theta}^{2}}{\sigma_{\theta}^{2}+\sigma_{\epsilon}^{2}}\left(s^{\prime}+\gamma c\right)$.

In terms of unobservable $s$, the equation is rearranged to

$E_{A}=\frac{\sigma_{\epsilon}^{2}}{\sigma_{\theta}^{2}+\sigma_{\epsilon}^{2}} \bar{\theta}^{\prime}+\frac{\sigma_{\theta}^{2}}{\sigma_{\theta}^{2}+\sigma_{\epsilon}^{2}} s-\frac{\sigma_{\theta}^{2}}{\sigma_{\theta}^{2}+\sigma_{\epsilon}^{2}}(1-\gamma) c$

If $\gamma=1$, participants suffer from no anchoring bias and the anchored estimate $E_{A}$ converges to the rational estimate $E_{R}$ as in Eq. (5). As $\gamma$ is smaller, the anchoring bias becomes severer. Concerning a typical Chinese firm that first issues foreign and then domestic A-shares, $c>0$ and $E_{A}<E_{R}$. 
The anchoring bias thus incorporates a downward bias into the A-share offer price and adds to A-share underpricing.

\subsubsection{Underpricing for the anchored estimate}

The underpricing of the anchored estimate is

$\theta-E_{A}=\frac{\sigma_{\epsilon}^{2}}{\sigma_{\theta}^{2}+\sigma_{\epsilon}^{2}}\left(\theta-\bar{\theta}^{\prime}\right)-\frac{\sigma_{\theta}^{2}}{\sigma_{\theta}^{2}+\sigma_{\epsilon}^{2}} \epsilon+\frac{\sigma_{\theta}^{2}}{\sigma_{\theta}^{2}+\sigma_{\epsilon}^{2}}(1-\gamma) c$

The expected underpricing is

$E\left[\theta-E_{A}\right]=\frac{\sigma_{\epsilon}^{2}}{\sigma_{\theta}^{2}+\sigma_{\epsilon}^{2}}\left(\bar{\theta}-\bar{\theta}^{\prime}\right)+\frac{\sigma_{\theta}^{2}}{\sigma_{\theta}^{2}+\sigma_{\epsilon}^{2}}(1-\gamma) c$

A comparison between Eq. (14) and Eq. (7) reveals that for Chinese firms first issuing foreign and then A-shares, $c>0$ and $E\left[\theta-E_{A}\right]>E\left[\theta-E_{R}\right]$. It suggests that the foreign share price plays a harmful anchoring role as it further exacerbates the A-share underpricing. The anchoring effect could also exert a beneficial influence in certain cases. For instance, if Chinese firms first issue domestic A-shares and then foreign shares, $c<0$ and the anchoring role played by the first-issued A-share price actually helps to reduce the underpricing of the second-issued foreign share.

The variance of the anchored underpricing is

$\operatorname{Var}\left[\theta-E_{A}\right]=\frac{\sigma_{\epsilon}^{2}}{\sigma_{\theta}^{2}+\sigma_{\epsilon}^{2}} \sigma_{\theta}^{2}=\operatorname{Var}\left[\theta-E_{R}\right]<\operatorname{Var}\left[\theta-\bar{\theta}^{\prime}\right]$

It follows that although anchoring may affect the expected underpricing, it does not produce additional volatility in underpricing. The rational is that although the anchoring bias produces directional bias in the conditional estimate, this bias is consistently upward or downward such that the volatility of underpricing does not increase. This is consistent with the intuition that with a readily observable foreign share price as a reference, the degree of A-share underpricing of cross-listed firms is more predictable than that of firms without such a reference. It attests to the beneficial informational role from a different perspective. 


\subsection{Dual-role played by the reference price}

We model the net effect brought by the existence of a foreign share price by comparing the anchored underpricing with the unconditional underpricing:

$$
\left(\theta-E_{A}\right)-\left(\theta-\bar{\theta}^{\prime}\right)=\frac{\sigma_{\theta}^{2}}{\sigma_{\theta}^{2}+\sigma_{\epsilon}^{2}}(1-\gamma) c-\frac{\sigma_{\theta}^{2}}{\sigma_{\theta}^{2}+\sigma_{\epsilon}^{2}} \epsilon-\frac{\sigma_{\theta}^{2}}{\sigma_{\theta}^{2}+\sigma_{\epsilon}^{2}}\left(\bar{\theta}-\bar{\theta}^{\prime}\right)
$$

The first component on the right hand side of Eq. (16) represents the anchoring role played by the foreign share price. For Chinese firms first issuing A- and then foreign shares, $c>0$ and the anchoring effect adds to the underpricing in the A-share issuance. The second and third components represent the informational role played by the foreign share price. The second component shows the informational role conditioning on the sign of the realized signal $s$. If the price of the first issued foreign share, after adjusting for the valuation difference between the two segmented markets, is higher than the true value of the second issued A-share, the realized $\epsilon$ is positive. The reference price then works to raise the offer price and reduce underpricing. Conversely, if the realized $\epsilon$ is negative, the reference price depresses the offer price and further exacerbates underpricing. The third component shows the unconditional contribution of the signal: regardless of the sign of the signal, the presence of signal itself helps to reduce the underpricing proportionally. Overall, whether the reference price increases or reduces underpricing of the follow-on A-share issuance depends on the net effect of the possibly harmful anchoring effect and the beneficial informational effect.

\subsection{The hypothesis development}

In this section, we develop testable hypotheses for cross-listed Chinese firms that first issue foreign shares and then domestic A-shares. First, we hypothesize that the price of first issued foreign share serves as an informative reference for pricing the second issued A-share. According to Eq. (10) and (11), the estimated A-share valuation is positively associated with the observable foreign share valuation $s^{\prime}$ and the valuation difference $c$, regardless of whether market participants suffer from the anchoring bias. Empirically, $s^{\prime}$ is proxied by the foreign PE ratio observed before 
the A-share pricing. We use PE ratios instead of price levels since PE ratios are more comparable across firms. The anchored estimate $E_{A}$ is proxied by the A-share's offer PE ratio, and the rational estimate $E_{R}$ is proxied by the aftermarket PE ratio observed in the A-share market after the Ashares are listed. The testable hypothesis is:

Hypothesis 1. For Chinese firms that first issue foreign shares and then A-shares, at the A-share issuance, ceteris paribus, the A-share's offer PE ratio and aftermarket $P E$ ratio are positively associated with the foreign share PE ratio and the valuation differences between the A-and foreign shares.

We test the anchoring hypothesis by comparing the coefficients on $c$ in Eq. (11) and (10). When we regress $E_{R}$ and $E_{A}$ on the foreign share valuation $s^{\prime}$ and the valuation difference $c$, we expect the relation between $E_{A}$ and $c$ to be weaker than that between $E_{R}$ and $c$. The hypothesis is:

Hypothesis 2. For Chinese firms that first issue foreign shares and then A-shares, at the A-share issuance, ceteris paribus, the positive association between the A-share's offer PE and the valuation difference is weaker than that between the aftermarket PE and the valuation difference.

Following Eq. (14), if investors suffer from the anchoring bias such that $\gamma<1$, the A-share underpricing is expected to be positively associated with the valuation difference $c$. The testable hypothesis is:

Hypothesis 3. For Chinese firms that first issue foreign shares and then A-shares, with the presence of anchoring effect, ceteris paribus, the A-share underpricing is positively associated with the valuation difference between the A- and foreign shares.

The psychological literature proposes that the anchoring heuristic persists because it helps to solve complex problems in a cost-effective way. We try to identify scenarios in which participants have different propensities to reply on the anchoring heuristic. According to Eq. (14), a higher $\gamma$, which indicates a weaker anchoring propensity, will result in a less positive association between underpricing and the valuation difference. We formalize the above reasoning as: 
Hypothesis 4. For Chinese firms that first issue foreign shares and then A-shares, when participants are less likely to resort to the anchoring heuristic, ceteris paribus, the positive association between the A-share underpricing and the valuation difference is weaker.

Finally, Eq. (14) suggests that a higher $\sigma_{\theta}^{2}$ and a lower $\sigma_{\epsilon}^{2}$, indicating greater valuation uncertainty for the second issued A-share and higher precision for the foreign share valuation $s^{\prime}$, lead to a stronger positive association between the A-share underpricing and the valuation difference. Accordingly, we have:

Hypothesis 5. For Chinese firms that first issue foreign shares and then A-shares, when the Ashare valuation is more uncertain or/and the foreign share valuation is more precise, ceteris paribus, the positive association between the A-share underpricing and the valuation difference is stronger.

\section{Baseline results}

\subsection{Data and sample distribution}

In the empirical tests, we use a unique dataset of 80 Chinese firms that first issued B- or Hshares and then domestic A-shares during the period from January 1, 1992 to December 31, 2010. ${ }^{3}$ We check IPO prospectus to ensure that upon the A-share pricing, their corresponding $\mathrm{B}$ or $\mathrm{H}$ shares have been publicly tradable with prices available. ${ }^{4}$ For firms that first issue foreign B- or H-shares and then domestic A-shares, we manually collect the offering details on the A-, B-, and $\mathrm{H}$-share issuance from IPO prospectuses, listing announcements, other public announcements, and news reports. We also refer to the IPO database provided by the GuoTaiAn Company (GTA). We

\footnotetext{
${ }^{3}$ Some might argue that it is desirable to expand our current sample to include Chinese firms cross-listed in the United States, Singapore, and the United Kingdom. However, most foreign shares of that kind are American Depository Receipts (ADRs), which are repackaged B-/H- shares and issued later than or simultaneously with B-/H-shares. We argue that the B-share market and Hong Kong market are integrated to the global market. At ADR issuance, B$/ \mathrm{H}$-share prices can be direct reference for the pricing of ADRs and the anchoring bias arguably has a minimal impact. We thus focus on Chinese firms that are cross-listed on B-share or Hong Kong market only.

${ }^{4}$ For several firms that first issued B-shares and then A-shares according to the listing date reported by CSMAR, we find that their A-share prices were actually determined before B-shares were priced after a close examination of their prospectus. We eliminate these observations.
} 
retrieve the daily stock price and return data for the A- and B-shares from China Stock Market Trading Research Database (CSMAR) maintained by GTA, and daily PE data from DataStream. We obtain financial statement data from GTA. We obtain the daily price, return, and PE data for the H-shares from DataStream.

Table 1 shows the distribution of sample firms across industries and years. We present statistics for the full sample in Panel A and find that firms in the industrial and utility industries dominate the sample. Sub-period statistics reveal that about half of the sample firms issued A-shares during the earliest subperiod from 1992 to 1998. Among the full sample, 53 firms first issued H-shares on the Hong Kong exchange and then A-shares on the Chinese securities market (subsample of first-Hthen-A firms), and 27 firms first issued B-shares then A-shares (subsample of first-B-then-A firms), with statistics shown in Panels B and C, respectively. ${ }^{5}$ Figure 2 plots the number of A-share IPOs of sample firms by year. The number of IPOs varies over years. ${ }^{6}$ A-share listings of first-B-then-A firms are concentrated in the first half of the sample period. The last first-B-then-A firm issued its A-shares in 2001, before the B-share market was opened to Chinese domestic investors. There were no A-share issuances in 2004 due to regulatory restrictions, whereas year 2007 witnessed 12 IPOs by firms that first issued H- and then A-shares.

\subsection{The proxy for the valuation difference $c$}

Following Errunza and Miller (2000), we use the realized buy-and-hold returns to proxy for the cost of capital. This measure essentially uses the ex post realized return to proxy for the ex

\footnotetext{
${ }^{5}$ Among the 80 samples, 13 firms issued A-shares more than five years after their respective foreign share issuances. Two firms with extremely long time lags are Sichuan Expressway, which listed its H-shares in October 1997 and its A-shares in July 2009, and Guangshen Railway, which listed its H-shares in May 1996 and its A-shares in December 2006. Seven firms issued their A-shares within three months after their respective foreign-share issuances. Jiaoda Kunji High-Tech issued its A-shares on December 7, 1993, within one month after its H-share issuance.

${ }^{6}$ Most Chinese firms first issued foreign- and then A-shares for at least four reasons. First, at the beginning of the Chinese financial reform in the 1990s, the A-share market was in its infancy. Firms intended to extract information from the foreign share issuance to promote the pricing efficiency in the subsequent A-share issuance. Second, when the A-share market was underdeveloped in the 1990s, Chinese firms had to rely on the more developed Hong Kong market for a large issuance. Third, most cross-listed firms are state-owned firms. H-share issuance is viewed as a political achievement that could help CEO promotion. Forth, by first launching an IPO in the H-share market, a firm sends out a positive signal to investors, as the listing requirements are more stringent in Hong Kong. Please refer to Tian (2011) and Fan et al. (2007) for more institutional details on the development of Chinese financial system.
} 
ante expected return. As shareholders of A- and foreign shares issued by the same firm have exactly the same cash flow rights and voting rights, the prevailing A-share premium over foreign shares is attributable to different costs of capital required in respective segmented markets. We use the buy-and-hold return over a one-year period beginning one day after the A-share listing. The difference in the returns on the A-share $($ BHRet_A) and the foreign share $($ BHRet_F $)$ is used to measure the valuation difference. Arguably, as the A-share price is usually higher than the price of corresponding foreign share, BHRet_A tends to be lower than BHRet_F. Consequently, the valuation difference $c$, as defined in Section 3, is positive.

Panel A of Table 2 shows that the average one-year return on A-shares is only $2.67 \%$, much lower than the average return of $28.40 \%$ on the corresponding foreign shares. ${ }^{7}$ Untabulated paired t-test reveals that this difference is statistically significant.

\subsection{The informational role played by the foreign share price}

First, we align our research with the literature on the informational role played by the reference price. We argue that market participants possibly suffer from the anchoring bias when determining the A-share offer price. Thus, we use the offer PE ratio to proxy for $E_{A}$, the anchored estimate. In addition, by assuming an efficient secondary market, we use the PE ratio observed one month after the A-share listing to proxy for $E_{R}$, the rational estimate. ${ }^{8}$

We run the following regressions to test Hypothesis 1:

$$
\begin{aligned}
& \text { PE_Aft1m }=a_{0}+a_{1} \text { DFBTA }+a_{2} T+a_{3} \text { PE_MKT }+a_{4} P E_{-} F++a_{5} \text { BHRet_F }+a_{6} \text { BHRet_A }+\varepsilon,(17 \\
& \text { PE_Offer }=b_{0}+b_{1} D F B T A+b_{2} T+b_{3} P E_{-} M K T+b_{4} P E_{-} F++b_{5} \text { BHRet_F }+b_{6} \text { BHRet_A }+\epsilon .(18
\end{aligned}
$$

\footnotetext{
${ }^{7}$ Two firms are newly-listed and thus do not have sufficiently long trading histories to calculate the one year buyand-hold returns. One sample firm, Jilin Chemical Industrial Co., was delisted from the Hong Kong market three years after its A-share listing, which does not incorporate the survivorship bias into the one-year buy-and-hold returns.

${ }^{8}$ We choose this aftermarket PE ratio for several reasons. First, the PE ratio on the first trading day may contain any under- or over-reactions as the A-share market may not be fully rational. Second, the price support provided by the underwriters usually ends by the end of the first trading month. The distortion brought about by the price support will thus disappear one month after the A-share listing. Third, an aftermarket PE that is too far away from the listing is not appropriate as it could be affected by noise in the aftermarket. As the time lag between the PE ratio and the A-share listing increases, the PE ratio becomes less relevant to the rational valuation level at the A-share issuance.
} 
In model (17), the dependent variable is the aftermarket PE, the proxy for $E_{R}$. In model (18), the dependent variable is the offer PE ratio, the proxy for $E_{A} .{ }^{9}$ In both models (17) and (18), as well as in the following regressions, we include a dummy variable DFBTA, which takes the value of one for the first-B-then-A subsample firms and zero for the first-H-then-A subsample firms. The control of DFBTA helps to address the concern that the anchoring propensity might differ in the $\mathrm{B}$ - and $\mathrm{H}$-share markets. Besides, we include a year $\mathrm{T}$ variable to control the general regulatory improvements in Chinese securities over time. $T$ takes the value of 1 for A-share IPOs listed in 1992, 2 for 1993, all the way up to 19 in $2010 .{ }^{10}$ First, we estimate models (17) and (18) separately using the cross-section of 80 sample firms that first issued foreign shares and then A-shares. We assume that the A-share offer price is determined five days before the A-share listing and search for important information available at that time. $P E_{-} M K T$ is the market-level PE ratio in the A-share market five days before the A-share listing, and we use it to control for the aggregate valuation level in the A-share market. $P E_{\_} F$ is the issuer's foreign share PE ratio observed five days before the Ashare listing, and we use it to proxy for $s^{\prime}$. BHRet_F and BHRet_A are the one-year buy-and-hold returns of the foreign share and the A-share, respectively. The difference between BHRet_F and BHRet_A is the proxy for the valuation difference $c$. According to Hypothesis 1 , we expect the coefficient on PE_F to be positive in both models, and the coefficients on BHRet_F and BHRet_A to be positive and negative, respectively.

We report the regression results in columns (1) and (2) of Table 3. We find that both the aftermarket PE and the offer PE are positively associated with $P E \_F$, strongly supporting the informational role played by the foreign share price in pricing the A-share. Moreover, the aftermarket PE is positively associated with $B H R_{e} t_{-} F$ and negatively associated with $B H R e t_{-} A$. In contrast, we find no statistically significant relation between $P E_{-} O f f e r$ and $B H R e t_{-} F$ or $B H R e t_{-} A$, consistent

\footnotetext{
${ }^{9}$ The offer PE ratio is self-reported by Chinese issuers, who can selectively choose to report either the fully-diluted $\mathrm{PE}$ after issuance, the weighted-average PE after issuance, or the fully-diluted PE before issuance. We assign value to the offer PE following such a sequence.

${ }^{10} \mathrm{We}$ could also include a set of year dummies into the regression. Such an approach, however, will substantially reduce the degree of freedom in the regression as our sample size is quite small. As a compromise, we use a single Year $T$ variable to control the unknown time-varying effect. We also perform an alternative robustness check by including year dummies, and the untabulated results are qualitatively similar.
} 
with Hypothesis 2 that $E_{R}$ is associated with both $s^{\prime}$ and $c$ whereas $E_{A}$ is only associated with $s^{\prime}$. The insignificant coefficient on DFBTA indicate that there is no significant difference in the Ashare valuation between firms with B- and $\mathrm{H}$-shares. The coefficient on $T$ is also indistinguishable from zero, suggesting that there is no significant change in PE_Offer over time. ${ }^{11}$

To formally test Hypothesis 2, we jointly estimate models (17) and (18) by forcing $a_{j}=b_{j}, j=$ $0, \ldots, 4$. We report the estimation results in columns (3) and (4) of Table 3. We test the null hypothesis that $a_{4}=b_{4}$ and $a_{5}=b_{5}$ and report the Wald-statistics in column (5). The results show that the association between PE_Aft1m and BHRet_F is significantly more positive than that between PE_Offer and BHRet_F, and that the association between PE_Aft1m and BHRet_A is marginally more negative than that between PE_Offer and BHRet_A. The result suggests that the relation between $E_{R}$ and $c$ is significantly stronger than that between $E_{A}$ and $c$, consistent with Hypothesis 2.

\subsection{The anchoring role played by the foreign share price}

The evidence discussed in Section 4.3 hints the existence of the anchoring effect. In a costeffective way, decision markers tend to begin with an easily available starting point and then make adjustment to get a final estimate. We argue that market participants tend to adopt this anchoring and adjustment framework in determining the A-share offer price to simplify the task on hand. The cross-listed foreign share, due to its similarity and prominence, is naturally the starting point. In this section, we perform analysis within the anchoring-and-adjustment framework and investigate the extent of the insufficient adjustment.

\footnotetext{
${ }^{11}$ The number of observations falls below the full sample size of 80 in regressions due to missing values on some key variables. See Table 2 for detailed information. E.g., in column (1) of Table 3, PE_MKT is missing for three firms that issued A-shares in late 2010 and for one firm that experienced thirteen days of market holidays right before its A-share issuance. $P E_{-} F$ is missing for one firm, which has infrequent B-share trading before its A-share issuance. BHRet_F and BHRet $A$ are missing for two firms, respectively, which do not have sufficiently long trading histories to calculate the one year buy-and-hold returns. In column (2), PE_Offer, the dependent variable, is missing for six firms that did not report their offer PE ratio in IPOs conducted in the early 1990s.
} 


\subsubsection{Upward adjustment}

We use the offer premium to measure the magnitude of adjustment made in the offering process. Prem_Offer is the A-share offer price over the foreign share closing price five days before the Ashare listing and then minus one. This premium is the percentage of the upward adjustment made by decision makers, which is possibly insufficient due to the anchoring bias.

Panel A of Table 2 shows that, after adjusting for the exchange rate, the A-shares on average are offered at a price $86 \%$ higher than that of the corresponding foreign shares, which is significantly different from zero. We also calculate a market-aggregate A-foreign valuation premium Prem $M K T$, using the closing prices of all cross-listed AB shares or AH shares five days before the A-share listing. Table 2 shows that the average Prem_MKT is $249 \%$, which is much higher than the average offer premium (86\%), indicating that the upward adjustment made in the offer premium is likely to be insufficient.

Market participants should make adjustments for the valuation difference between the segmented markets. For a cross-listed firm, the valuation difference between its A- and foreign shares is attributable to the difference in costs of capital in the two markets. We use the following model in the cross-sectional regression:

Prem_Offer $=a_{0}+a_{1}$ Prem_MKT $+a_{2}$ DFBTA $+a_{3} T+b_{1}$ BHRet_F $+b_{2}$ BHRet_A $+\varepsilon$,

where the independent variables are as defined in model (17). Ceteris paribus, we expect the offer premium to be higher when the cost of capital is lower for the A-share and/or higher for the foreign share. We thus expect $b_{1}$ to be positive and $b_{2}$ to be negative.

We report the regression results in column (1) of Table 4. The coefficient on Prem $M K T$ is significantly positive, suggesting that the prevailing market-aggregate A-foreign premium strongly affects the offer premium. As expected, the coefficient on BHRet_F is significantly positive and the coefficient on BHRet $A$ is negative, although insignificant, indicating that decision makers take the valuation difference $c$ at the firm level into consideration at least partially. The coefficient on the year variable $T$ is significantly negative, suggesting that the spread between the A-share offer price and corresponding B-/H-share trading price narrows in the recent period. 


\subsubsection{Insufficient adjustment}

Now we examine whether the upward adjustment is sufficient, i.e., whether the offer premium is sufficiently high. According to Eq. (14), if market participants are subject to the anchoring bias and thus adjust for the valuation difference $c$ only partially in determining the A-share offer price, the level of A-share underpricing will be positively associated with $c$. We measure the underpricing $\left(I R \_A\right)$ by the IPO first-day return, which is the percentage difference between the first-day closing price and the offer price.

Table 2 provides the statistics of the A-share underpricing for the 80 sample firms. Panel A shows that, on average, these sample firms with foreign shares still suffer from great underpricing at the A-share issuances, with an average first-day return of $93 \%$ and a median of $76 \%$. We use all available IPO data recorded in CSMAR to update the statistics reported by Chen et al. (2008). After eliminating outliers with a first-day return higher than 100 (10000\%), we end up with a sample containing 2,105 IPOs from 1992 to 2010 with an average underpricing of $187 \%$ and a median of 95\%. A comparison of A-share underpricing between cross-listed firms and typical Chinese firms hints that the benefits brought by foreign shares as references are rather marginal, which may be due to the harmful anchoring effect.

We run the following regression to test the anchoring Hypotheses 3, 4 and 5:

$$
\begin{aligned}
I R_{-} A= & a_{0}+a_{1} \text { DFBTA }+a_{2} T+a_{3} \text { Prem_Resid }+b_{1} \text { BHRet_F }+b_{2} \text { BHRet_A } \\
& +c_{1} \text { BHRet_F } \times \text { Dummy }+c_{2} \text { BHRet_A } A \text { Dummy }+\varepsilon
\end{aligned}
$$

where Prem_Resid is the residual from model (19), used to control for the upward adjustment made in the offering process. We use the residual rather than Prem_Offer to mitigate the multicollinearity problem brought by the structural relationship as modeled in Eq. (19). According to Hypothesis 3, we expect the underpricing to be positively associated with $c$ if the anchoring effect exists such that the upward adjustment is insufficient. We thus expect $I R \_A$ to be positively associated with BHRet_F and negatively associated with $B H \operatorname{Ret} \_$, which results in a positive $b_{1}$ and negative $b_{2}$.

We use three dummies to proxy for investors' anchoring propensity to test the anchoring Hypothesis 4. Tversky and Kahneman (1974) suggest that market participants are less likely to rely 
on heuristics when more information is available. As large-scale issuances usually gain higher media coverage, which helps to produce more information, we expect investors to have weaker anchoring propensity in these cases. We set a dummy DLarge to be equal to one when the amount of inflation-adjusted gross proceeds collected from the A-share issuance is greater than the sample median and zero otherwise. Chapman and Johnson (2002) advise that monetary incentives help to reduce behavioral biases. A related scenario is when the state ownership is substantially diluted through an IPO. New share issuance is equivalent to the disposal of state-owned shares in this privatization process. Most managers in the state-owned enterprises used to be bureaucrats who care about their political future. In this situation, the incentive to reduce "money left on the table" is strong enough for managers to offset the satisfaction from the potential appreciation of the retained shares (Loughran and Ritter, 2002). Therefore, we expect the anchoring bias to be weaker when the state ownership is diluted to a greater extent. We thus propose a second dummy, $D \Delta S O$, which takes the value of one when the reduction in state-ownership following the A-share issuance is greater than the sample median and zero otherwise. Loughran and Ritter (2004) argue that issuers have changed their objective function to focus less on reducing underpricing but more on non-price services such as analyst coverage. Since prestigious underwriters could satisfy issuers though competitive non-price services, they have arguably weaker incentives to struggle through the "painful" pricing-adjustment process as suggested in Section 3.2 and thus care less about "money left on the table". Therefore, we expect underwriters with better reputation to be more prone to suffer from the anchoring bias. We use the underwriting fees to proxy for the underwriter reputation, with higher fees representing better reputation. The dummy DFee takes the value of one when the flotation cost as a percentage of the gross proceed in the A-share issuance is smaller than the sample median and zero otherwise. All these three dummies are ex ante variables, known before the A-share issuance. And for all the three dummies, the expected coefficients on their interaction terms with $B H R e t \_F$ and $B H R e t \_A$ have signs opposite to that of the coefficients on $B H R e t \_R$ and BHRet $A$. Thus, we expect $c_{1}$ to be negative and $c_{2}$ to be positive.

The last dummy, $D \sigma_{\theta}^{2}$, is an ex-post variable, used to test the anchoring Hypothesis 5 . We use 
the turnover ratio on the first trading day of A-shares to proxy for the valuation uncertainty, with a higher turnover ratio representing greater valuation uncertainty (higher $\sigma_{\theta}^{2}$ ). The dummy variable $D \sigma_{\theta}^{2}$ takes the value of one when the turnover is higher than the sample median and zero otherwise. According to Hypothesis 5, the anchoring bias has greater influence over the offer price when the A-share valuation involves more uncertainty. We thus expect the signs of the coefficients on the interaction terms to be the same as those of the coefficients on BHRet_F and BHRet $\_$. Therefore, when $D \sigma_{\theta}^{2}$ is used, we expect $c_{1}$ to be positive and $c_{2}$ to be negative.

We report the regression results of model (20) in columns (2) to (7) of Table 4. We first examine whether underpricing is associated with the valuation difference measured by BHRet_F and BHRet $A$. The result in column (2) shows that the coefficient on BHRet $A$ is significantly negative. We further control for the offer premium in column (3) to capture the upward adjustment that is already made in the offering process. The coefficient on BHRet_F is insignificant, whereas the coefficient on BHRet_A remains significantly negative. It suggests that market participants have fully taken the relative cost of capital of foreign shares into consideration, which is not surprising as the foreign share valuation is quite evident. However, they tend to overlook the cost of capital of Ashares, which is more difficult to estimate. As a result, they under-react to the valuation information associated with the A-shares, but not to that associated with the foreign shares. The evidence is consistent with the insufficient adjustment argument and supports Hypothesis 3. Throughout columns (2) to (8), the coefficients on DFBT A and $T$ are both indistinguishable from zero.

We then include the interaction terms between dummies and BHRet_F and BHRet $A$ into model (20) and report the results in columns (4) to (8). In column (4), where the interactions with DLarge are included, the coefficients on BHRet_F, BHRet_A and the interaction terms are all significantly different from zero with predicted signs. The results lend strong support to Hypothesis 4 by revealing that market participants are less likely to suffer from the anchoring bias if the issuances are of a large scale. The interactions with dummy $D \Delta S O$ are included in column (5). BHRet $A$ has a significantly negative coefficient and the interaction term between BHRet $A$ and $D \Delta S O$ has a significantly positive coefficient. It suggests that when the state ownership is diluted to a greater 
extent because of new share issuance, the decision makers have stronger incentives to make a more sufficient adjustment. The evidence is also consistent with Hypothesis 4. In column (6), we include the interactions with DFee. As expected, the coefficient on BHRet_F is significantly positive, and that on BHRet $A$ is significantly negative. The coefficients on the interaction terms are both statistically significant with predicted signs. This evidence further supports Hypothesis 4 by showing that more reputable underwriters, proxied by higher flotation costs charged, suffer from a stronger anchoring bias.

We add the interaction terms with dummy $D \sigma_{\theta}^{2}$ into the regression in column (7). The result shows that when the A-share valuation is less ambiguous with $D \sigma_{\theta}^{2}=0, I R \_A$ is not significantly associated with the proxies for the valuation difference $c$, indicating a weak anchoring effect. In comparison, when the A-share has greater valuation uncertainty with dummy $D \sigma_{\theta}^{2}=1$, the coefficient on BHRet_F is significantly more positive and that on $B H R e t \_A$ is significantly more negative, indicating that the anchoring bias exerts stronger influence in this case. The results support Hypothesis 5 .

Finally, we include the interaction terms of all four dummies with the buy-and-hold returns into the regression and report the result in column (8). Consistent with Hypothesis 3, even after the interaction terms with four dummies are included, the coefficient on BHRet_F is still significantly positive, and that on BHRet_A is significantly negative. Consistent with Hypotheses 4 and 5 , the coefficients on the interaction terms with DLarge and with $D \sigma_{\theta}^{2}$ remain statistically significant, indicating that both $D$ Large, a proxy for the degree of anchoring bias $\gamma$, and $D \sigma_{\theta}^{2}$, a proxy for the valuation uncertainty, affect the degree of the anchoring effect. ${ }^{12}$

In summary, the empirical evidence in Sections 4.3 and 4.4 supports the dual role hypothesis. For cross-listed firms, the foreign share valuation provides important information for pricing the Ashares. Cross-sectionally, the foreign share price predicts the A-share offer price and aftermarket

\footnotetext{
${ }^{12}$ The number of observations is less than the full sample size of 80 in regressions because of missing values on some key variables. See Table 2 and footnote 11 for more details. In addition, DFee is missing for four sample firms that do not report their underwriting fees. $D \sigma_{\theta}^{2}$ is missing for one sample firm that has missing first-day turnover in CSMAR.
} 
price. Within the anchoring framework, market participants start from the foreign share price and adjust upward according to the difference in costs of capital between the two segmented markets. We argue that the adjustment is insufficient by showing that the A-share underpricing is associated with the difference in costs of capital, and that the association is stronger when the decision markers tend to suffer from a stronger anchoring bias and when the A-share valuation involves more uncertainty. ${ }^{13}$

\section{Robustness checks}

\subsection{Regulatory underpricing}

Tian (2011) argues that the pricing cap and strict quota system lead to "regulatory underpricing", contributing to the extremely high level of underpricing in China. He states that "in several internal guidelines issued during different periods, the CSRC [China Securities Regulatory Commission] sets the ceiling of the [PE] multiplier as 15 to 20 times earnings, which is the pricing cap of IPO shares." The relation between the existence of the regulatory cap and the level of underpricing, however, is ambiguous according to their empirical findings. To control for the possible effect of regulatory constraints, we check the offer PE of our sample firms. We consider firms with an offer PE around 15, 16, 18, and 20 times to be capped by regulation. ${ }^{14}$ Using this method, only 13

\footnotetext{
${ }^{13} \mathrm{Eq}$. (16) illustrates that the beneficial informational role and the harmful anchoring role of foreign shares have opposing impacts on the underpricing of corresponding A-shares. Hence the net influence of the existence of foreign shares on A-share underpricing is an empirical issue. We thus conduct a matching test, in which cross-listed firms are matched to firms without foreign shares but with similar A-share IPO characteristics in terms of industry, date of issuance, gross proceeds, and pre-IPO market returns. We find that firms with foreign shares have slightly lower underpricing than their matching firms without foreign shares. Moreover, the difference in underpricing between firms with foreign shares and matching firms is significantly negative when the valuation difference is mild, but close to zero when the valuation difference is large. The evidence suggests that the anchoring effect is weaker and tends to be dominated by the informational effect given lower valuation difference. When the valuation difference increases, the anchoring effect grows and offsets the informational effect. The matching test, however, has its weakness. The $\mathrm{H}$-share issuers are of great strategic importance to the government and are usually monopolies and very large, making it difficult to find perfect matches for them. We do not report the matching test results for brevity, and these results are available upon request.

${ }^{14}$ These multiples are the PE caps historically prevalent according to Tian (2011). We treat PEs within the range of [14.9,15.1], [15.9,16.1], [17.9,18.1), or [19.9, 20.1) as being capped. According to Tian (2011), the pricing cap is time-variant and applicable to all issuing firms at that time. Thus, our measure is imprecise and may mistreat some firms that just happen to issue at those multiples. Also, even if a firm issues at a PE higher than the cap, it may still be affected by the cap. Chinese issuing firms even have a certain degree of freedom in choosing the PE to report to
} 
out of the 80 sample firms are possibly capped. We use a dummy variable DCap to control for the regulatory constraint, which equals one for capped firms and zero otherwise. We add DCap into model (20) and examine whether the results reported in Table 4 are robust.

We report the regression results in Table 5. The coefficient on DCap is significantly negative across all columns, indicating that firms that are suspected to be capped actually have lower underpricing. It is hard to reconcile these results with the findings in Tian (2011), which argues that the pricing cap creates excess demand for securities and thus results in greater underpricing. After we control for DCap and other explanatory variables, the results remain similar to those reported in Table 4. Untabulated tests show that the results hold even after we control for individual cap dummies DCap15, DCap16, DCap18, and DCap20 in the regressions. It suggests that the regulatory constraint cannot fully account for the association between the A-share underpricing and the valuation difference.

It is interesting to note that the Security Law, which took effect in July 1999, stipulated that the share offer price should be determined through consultation between the issuer and the underwriter. CSRC explicitly abolished this pricing cap in June 10, 2009. Although the regulatory constraints may still exist in a less noticeable form, we expect them to be less relevant in the future.

\subsection{Sentiment}

In Section 4, we implicitly assume an efficient market in which the aftermarket A-share price represents the fair valuation and the first-day return fairly proxies for the correction of anchoring bias incurred in the primary market. Some might argue that the secondary market price can be biased upward due to sentiment. We contend that as long as the price errors created by sentiment are not systematically related to the difference in costs of capital, the results in Table 4 still support our insufficient adjustment and anchoring argument.

To control for the influence of time-varying sentiment, we follow Baker and Wurgler (2006)

CSRC (see Footnote 9), suggesting that the issuer can circumvent the cap to some extent by reporting a lower PE that is measured using alternative methods. 
to construct a sentiment index for the Chinese A-share market using data from CSMAR. ${ }^{15}$ We include Sentiment1 and Sentiment2 into model (20), and find only weak support for the sentiment argument. The results in Table 5 show that the coefficient on Sentimentl is significantly positive only in the parsimonious models in columns with even numbers. And the relation between the A-share underpricing and BHRet_A, BHRet_F and the interaction terms remain qualitatively unchanged. It is therefore difficult to argue that the results documented in Section 4 are simply driven by sentiment in the secondary market.

\subsection{Additional control variables}

In addition to the regulatory cap and the market sentiment, we control for several variables that have cross-sectional explanatory power for the underpricing.

We follow previous studies (e.g., Tian (2011)) to control for Lag_Ann_List, the log of the time lag in calendar days between the announcement of a prospectus and the actual listing date. This lag can be very long in China, and it reflects the lockup risk faced by investors in the primary market. We thus expect the A-share underpricing to be positively associated with Lag_Ann_List. Titman and Trueman (1986) show that the choice of auditor influences the amount of information produced before listing. We expect reputable auditors to help reduce information asymmetry and signal the quality of the firm, thus mitigating the underpricing. We include a dummy DAuditor to control for auditor identity, which equals one if the sample firm is audited by a Big Four auditing firm and zero otherwise. Following Welch (1989), we expect that the underpricing level

\footnotetext{
${ }^{15}$ We calculate the aggregate closed-end fund discount $(C E F D)$ at the end of each month using the daily closed-end fund data. We collect the monthly trading value and the market value of tradable shares and calculate the aggregated turnover ratio in the A-share market $(T U R N)$. We use the IPO data to calculate the number of IPOs (NIPO) and the average underpricing level (RIPO) in each month. We also calculate the share of equity issues in total equity and debt issues in each month $(S)$. A firm that pays cash dividends is treated as a dividend payer in that quarter. For each firm, we match its book value reported in the annual financial statement, which is assumed to be released at the end of April, to month-end market value to obtain the monthly market-to-book ratio. We then calculate the dividend premium $P^{D-N D}$, which is the log difference in the average market-to-book ratio between payers and non-payers. We estimate the principal components of the six proxies and their lags. We find that the first principal component explains $31 \%$ of the sample variance and the second principal component explains additional $16 \%$ of the variance. We compute the correlation between the first/second principal component and the current and lagged values of each proxy. Finally, we define Sentiment 1 as the first principal component of the correlation matrix of the six variables, each respective proxy's lead or lag, whichever has higher correlation with the first principal component. Similarly, Sentiment2 is defined for the second principal component.
} 
of previous foreign share issuance helps to leave a good taste in the mouth of investors and thus mitigates the A-share underpricing. We thus include the underpricing level of the previous foreign share issuance, $I R_{-} F$, to control for this signaling effect. $S O \%$ is the percentage of state ownership before the A-share issuance. Higher state ownership indicates separation of ownership and management, which is often associated with lower efficiency and thus predicts greater underpricing. Loughran and Ritter (2002) find that issuers under-react to public information such as market returns. Hence, we control for CRetM, which is the market return cumulated over a two-week period ending one week before the A-share listing. We expect $I R \_A$ to be positively associated with CRetM. Lag_FA is the log of time lag between the A-share and previous foreign share listing. In a market that is not fully efficient, a longer trading history of foreign shares might help to produce more information and thus reduce the A-share underpricing. We thus expect the coefficient on Lag_FA to be negative. Finally, we define Ratio_AF as the proceeds collected from the A-share issuance divided by those from the $\mathrm{H}$-share issuance, after the adjustment of exchange rates and inflation. A lower Ratio $A F$ implies higher probability of excess demand for A-shares, and predicts greater underpricing.

We show the descriptive statistics of the control variables in Panel A of Table 5. We then include these control variables in model (20) and present the multivariate regression results in Panel B. In columns (1) and (2), we include all control variables but no interaction terms. In the following columns, we include the interaction terms of buy-and-hold returns with the dummies DLarge, $D \Delta S O$, DFee and $D \sigma_{\theta}^{2}$. We report two versions of tests for each model specification. In odd columns, we include all control variables. As our sample size is small, using too many controls will reduce the model's explanatory power. Thus, we use the stepwise method to retain important variables only and report regression results in even columns.

The results in Panel B of Table 5 are similar to the baseline results in Table 4. The coefficient on BHRet $A$ is significantly negative in columns (1) to (4) and (6) to (8), and the coefficient on BHRet_F is significantly positive in columns (3), (4), and (7) to (10), strongly supporting Hypothesis 3. The coefficients on the interaction terms of buy-and-hold returns with DLarge and DFee 
are significant with predicted signs, as shown in columns (3), (4), (7) and (8), supporting Hypothesis 4. In columns (9) and (10), we include the interaction terms with $D \sigma_{\theta}^{2}$. As the A-share valuation involves less uncertainty with $D \sigma_{\theta}^{2}=0$, the coefficient on BHRet_F is significantly negative, indicating that decision makers actually overreact to the foreign share valuation in the adjustment stage. When $D \sigma_{\theta}^{2}=1$, however, the coefficient on the interaction term almost offsets the negative coefficient on BHRet $F$ and makes the coefficient on BHRet $A$ negative, suggesting under-reaction when the valuation uncertainty is high, consistent with Hypothesis 5.

Among the control variables, the coefficient on DFBT $A$ is significantly negative, suggesting that subsamples with $\mathrm{H}$-shares tend to suffer from higher A-share underpricing than those with B-shares. The coefficient on $T$ is significantly positive, suggesting higher underpricing in more recent years. The evidence is not surprising since we find that the spread between A- and B/H- share offer price is lower in recent period (Section 4.4.1), which might result from the growing bargaining power of retail investors who arguably suffer from a stronger anchoring bias. Consistent with previous studies, we find that the underpricing is negatively related to Proceed, indicating that a larger issuance tends to have lower underpricing. The coefficient on $\Delta S O$ is indistinguishable from zero. Fee is positively associated with underpricing, consistent with the agency argument of Loughran and Ritter (2004) given the assumption that IPOs with higher flotation costs are more likely to be underwritten by more reputable underwriters. The coefficient on $I R_{-} F$ is significantly negative in columns (1), (3), (4) and (5), indicating that the underpricing in an earlier foreign share issuance helps to reduce the underpricing in subsequent A-share issuance. The coefficient on Lag_FA is indistinguishable from zero. Consistent with Tian (2011), Lag_Ann_List is significantly positively related to underpricing. The coefficient on CRetM is significantly positive, suggesting that the offer price does not fully reflect information in the secondary market. The coefficient on DAuditor is significantly negative, suggesting that hiring a Big Four auditing firm helps to reduce underpricing. The coefficient on Ratio_AF is negative but insignificant. ${ }^{16}$

\footnotetext{
${ }^{16}$ We include Ratio_AF as when the A-float is small relative to the H-float, shortage of available stocks in the AIPO might lead to greater A-IPO underpricing. The insignificant coefficient on Ratio_AF, however, does not support such an argument. A possible explanation is that even though the ratio of A-share issuance is low, the absolute scale
} 


\subsection{The impact of QDII}

On April 13, 2006, the Chinese government announced the Qualified Domestic Institutional Investor (QDII) scheme, allowing Chinese institutions and residents to entrust certain Chinese commercial banks to invest on financial products overseas, but the investment was limited to fixed-income and money market products. On May 11, 2007, Chinese government announced a widening scope for QDII investment. Banks can now offer stock-related products under certain restrictions. By the end of February 2012, the total approved amount of QDII has grown to 75.2 billion U.S. dollar, which is greater than the approved capital amount of QFII. ${ }^{17}$

Arguably, QDII mitigates the investment barriers between the Chinese domestic market and the foreign market to some extent. Hence, the anchoring effect brought by foreign prices should be weaker after the implementation of the QDII scheme. In our sample, 13 firms listed their A-shares after May 11, 2007, and it would be quite difficult to perform meaningful tests on such a small sample. Thus, we rerun regression models (17), (18), (19) and (20) using sample firms that issued A-shares before May 11, 2007. In total, we have 67 sample firms. Untabulated results are similar to those in Tables 3 and 4, rendering support to our three hypotheses. The results suggest that before the QDII scheme could fully liberalize the Chinese stock market, the foreign share valuation still plays both an informational and anchoring role.

Given the fact that the aggregate quota allocated to QDII is only around $2.6 \%$ of the size of the A-share market, which was 2.9 trillion U.S. dollar at the end of February 2012, we argue that QDII still has a small scale and relatively limited influence. QDII alone is difficult to provide sufficient investable products for the Chinese domestic capital, wipe off the A-H premium, and eliminate the prevailing anchoring effect in the markets.

of A-share issuance is not necessarily small. For instance, Bank of China issued H-shares in June 2006 and A-shares in July 2006, and the amount of A-share proceeds was only $18 \%$ of the total proceeds (adjusted for exchange rate and inflation). However, the A-share proceed alone was as large as 20 billion Chinese Yuan (about 2.6 billion U.S. dollar), and over half of shares were sold to retail investors. For a typical A-share issuance in the Chinese market, the average proceed is only .9 million Chinese Yuan. Even for the 80 sample firms investigated in this study, the average A-share proceeds are only 5.9 billion Chinese Yuan. Hence, it is hard to argue A-share shortage in the case of Bank of China.

${ }^{17}$ The number is disclosed by the State Administration of Foreign Exchange of China, http://www.safe.gov.cn/. 


\subsection{Skewed variables}

In our sample, both Prem_Offer and IR $A$ are skewed to the right, with a skewness of 3.24 and 1.35 , respectively. To address the concern that the variables are not normally distributed, we perform additional tests to use the log version of the two variables $(\log ($ variable +1$))$ as dependent variables in models (19) and (20), respectively. The results remain similar to those reported in Table 4, rendering further support to our anchoring Hypotheses 3, 4, and 5.

\subsection{The influence of outliers}

In untabulated tests, we also try to eliminate the influence of outliers on our empirical results. We delete observations with first-day returns higher than $300 \%$ and redo all the tests in Tables 3 and 4. The results remain qualitatively unchanged, suggesting that the evidence documented in Sections 4.3 and 4.4 is not purely driven by the extreme values of variables.

\subsection{Measurement period of buy-and-hold returns}

As a further robustness check, we measure the cost of capital based on buy-and-hold returns calculated over different holding periods. Specifically, we measure costs of capital of A-shares and foreign shares using six-month, two-year, or three-year buy-and-hold returns. The alternative methods of measuring cost of capital do not alter our main results reported in Tables 3 and 4 .

\section{Conclusion}

In this study, we propose that for a firm cross-listed in multiple markets, in pricing its subsequently issued share, the price of its first issued share plays both an informational and anchoring role. Past studies have examined the informational role of the reference price extensively, and our study contributes to the literature by investigating the anchoring role. We develop a model to incorporate the beneficial informational role and the possible harmful anchoring role played by the reference price. Our empirical investigation based on a group of Chinese firms that first issue foreign shares and then domestic A-shares supports all model predictions. We find evidence showing that market participants fail to fully adjust for the difference in costs of capital between the 
A-share and foreign-share markets due to the anchoring bias, resulting in the A-share offer price being anchored to the foreign share price.

This study has important implications for the international financing literature. In the trend toward global integration, more and more firms are striving to raise capital in both foreign and domestic markets. We remind issuers that the informational role played by the price of an existing share is limited in the cross-listing scenario, as cost of capital differs between segmented markets, and that the anchoring effect may weaken the informational role of the reference price.

Our study has general implications for cross-listed firms beyond IPOs. The process of collecting information in the primary market is notoriously challenging. When the valuation uncertainty is high, market participants tend to rely on certain heuristics to simplify the valuation process. In this situation, an informative reference could help to reduce valuation uncertainty. However, decision-makers need to be cautious about the underlying differences between the target and the reference. As shown in this study, insufficient adjustment to new information leads to the anchoring effect, which will offset the information content of the reference.

Our study helps market participants to understand the influence of market segmentation on the pricing of cross-listed shares better. It has special implications for Chinese policy-makers by suggesting that the A-H "arbitrage" is not appropriate as long as the Chinese market is not fully liberalized. The "A+H" IPO mechanism, or issuing A- and H-shares simultaneously at the same price, is also inferior as it neglects the fact that investors require different rates of returns on the two markets.

This study also has its limitations. First, we have a small sample of only 80 cross-listed Chinese firms. The small sample itself limits the power of statistical tests. Second, the cost of capital is notoriously difficult to measure. Ex-post realized return may not be the perfect measure of cost of capital, but it is objective, easily observable, and has been widely used in the literature to proxy for cost of capital. Third, the Chinese stock market is not completely free from government intervention even after the legislation of the Security Law in 1999, as CSRC may still influence the A-share pricing in a less noticeable way. 


\section{References}

Arquette, G. C., Brown, Jr., W. O., Burdekin, R. C., 2008. US ADR and Hong Kong H-share discounts of Shanghai-listed firms. Journal of Banking and Finance 32 (9), 1916-1927.

Baker, M., Wurgler, J., 2006. Investor sentiment and the cross-section of stock returns. Journal of Finance $61(4), 1645-1680$.

Cai, C. X., McGuinness, P. B., Zhang, Q., 2011. The pricing dynamics of cross-listed securities: The case of Chinese A- and H-shares. Journal of Banking and Finance 35 (8), 2123-2136.

Campbell, S. D., Sharpe, S. A., 2009. Anchoring bias in consensus forecasts and its effect on market prices. Journal of Financial and Quantitative Analysis 44 (2), 369-390.

Cen, L., Hilary, G., Wei, K. J., 2012. The role of anchoring bias in the equity market: Evidence from analysts' earnings forecasts and stock returns. Journal of Financial and Quantitative Analysis, Forthcoming.

Chan, K., Menkveld, A. J., Yang, Z., 2008. Information asymmetry and asset prices: Evidence from the China foreign share discount. The Journal of Finance 63 (1), 159-196.

Chang, E. C., Luo, Y., Ren, J., 2011. Ex-day returns for stock distributions: An anchoring explanation. Working paper, University of Hong Kong.

Chapman, G. B., Johnson, E. J., 2002. Incorporating the irrelevant: Anchors in judgments of belief and value. The psychology of judgment: Heuristics and biases. Cambridge University Press, New York.

Chen, Z., Choi, J. J., Jiang, C., 2008. Private benefits in IPOs: Evidence from state-owned firms. Working paper, Temple University.

Errunza, V. R., Miller, D. P., 2000. Market segmentation and the cost of capital in international equity markets. Journal of Financial and Quantitative Analysis 35 (4), 577-600.

Eun, E., Sabherwal, S., 2003. Cross-border listings and price discovery: Evidence from U.S.-listed Canadian stocks. Journal of Finance 58 (2), 549-575.

Fan, J., Wong, T., Zhang, T., 2007. Politically connected CEOs, corporate governance, and post-IPO performance of China's newly partially privatized firms. Journal of Financial Economics 84 (2), 330-357.

Fernald, J., Rogers, J. H., 2002. Puzzles in the Chinese stock market. Review of Economics and Statistics 3784 (3), 416-432.

Fernandes, N., Ferreira, M. A., 2008. Does international cross-listing improve the information environment. Journal of Financial Economics 88 (2), 216-244. 
Foerster, S. R., Karolyi, G. A., 1999. The effects of market segmentation and investor recognition on asset prices: Evidence from foreign stocks listing in the United States. Journal of Finance 54 (3), 981-1013.

George, T., Hwang, C. Y., 2004. The 52-week high and momentum investing. Journal of Finance 59 (5), 2145-2176.

Hayek, F. A., 1945. The use of knowledge in society. American Economic Review 35 (4), 519-530.

Krigman, L., Shaw, W. H., Womack, K. L., 1999. The persistence of IPO mispricing and the predictive power of flipping. Journal of Finance 54 (3), 1015-1044.

Loughran, T., Ritter, J. R., 2002. Why don’t issuers get upset about leaving money on the table in IPOs? Review of Financial Studies 15 (2), 413-443.

Loughran, T., Ritter, J. R., 2004. Why has IPO underpricing changed over time? Financial Management 33 (3), 5-37.

Loughran, T., Ritter, J. R., Rydqvist, K., 1994. Initial public offerings: International insights. Pacific-Basin Finance Journal 2, 165-199.

Purnanandam, A., Swaminathan, B., 2004. Are IPOs really underpriced? The Review of Financial Studies $17(3), 811-848$.

Shafir, E., Diamond, P., Tversky, A., 1997. Money illusion. Quarterly Journal of Economics 112 (2), 341374.

Tian, L., 2011. Regulatory underpricing: Determinants of Chinese extreme IPO returns. Journal of Empirical Finance 18 (1), 78-90.

Titman, S., Trueman, B., 1986. Information quality and the valuation of new issues. Journal of Accounting and Economics 8 (2), 159-172.

Tversky, A., Kahneman, D., 1974. Judgment under uncertainty: Heuristics and biases. Science 185 (4157), 1124-1131.

Wang, S. S., Jiang, L., 2004. Location of trade, ownership restrictions, and market illiquidity: Examining Chinese A- and H-shares. Journal of Banking and Finance 28 (6), 1273-1297.

Welch, I., 1989. Seasoned offerings, imitation costs, and the underpricing of initial public offerings. Journal of Finance 44 (2), 421-449. 


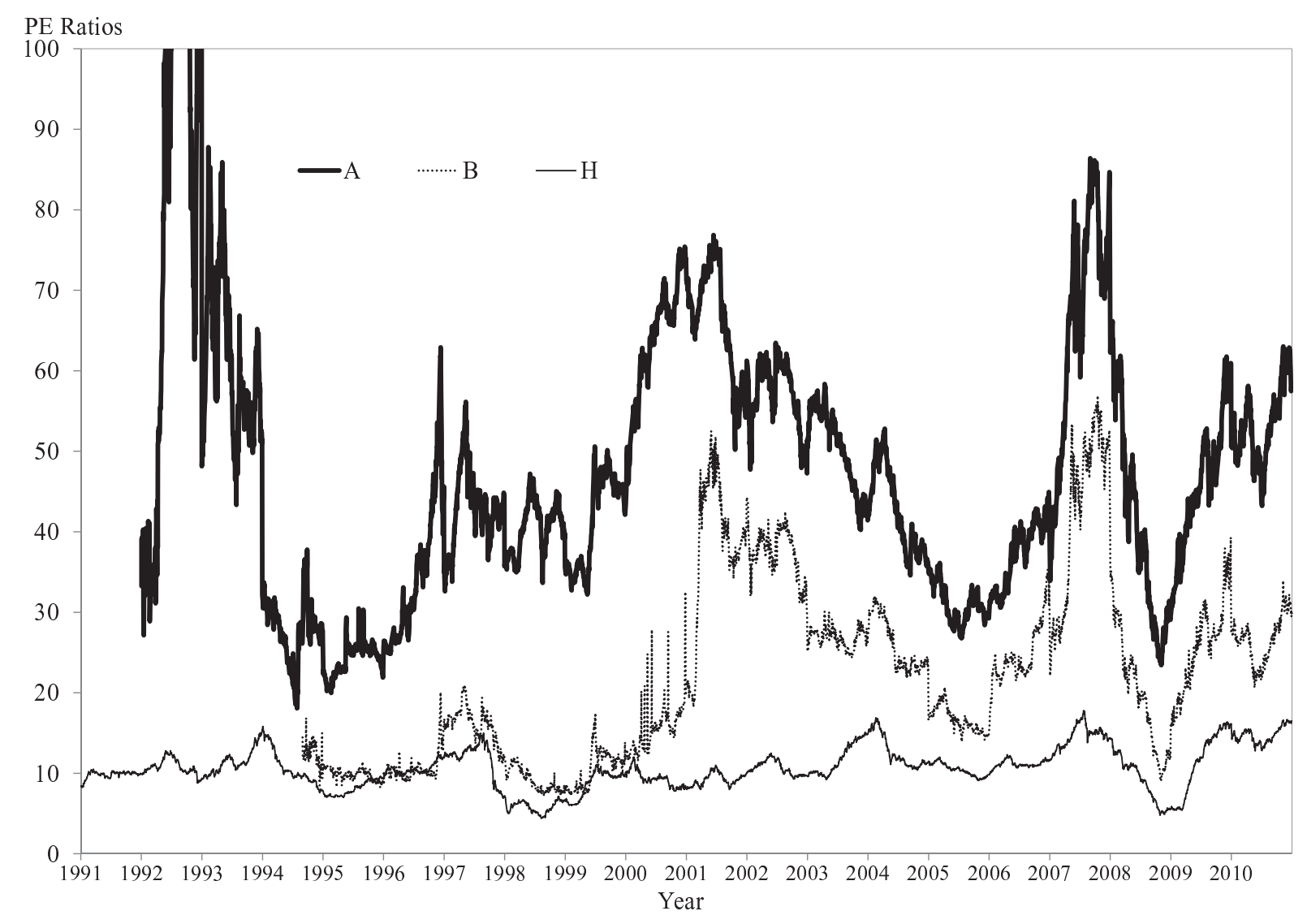

Figure 1: The median PE ratio in A-, B-share, and Hong Kong markets.

This figure plots the median price-to-earning (PE) ratios in Chinese domestic and foreign stock markets over time. The thick solid line represents the time-varying median of PE ratios in the A-share market, the thin dashed line plots the median of PE for B-share market, and the thin solid line plots the median of PE for the Hong Kong market. 


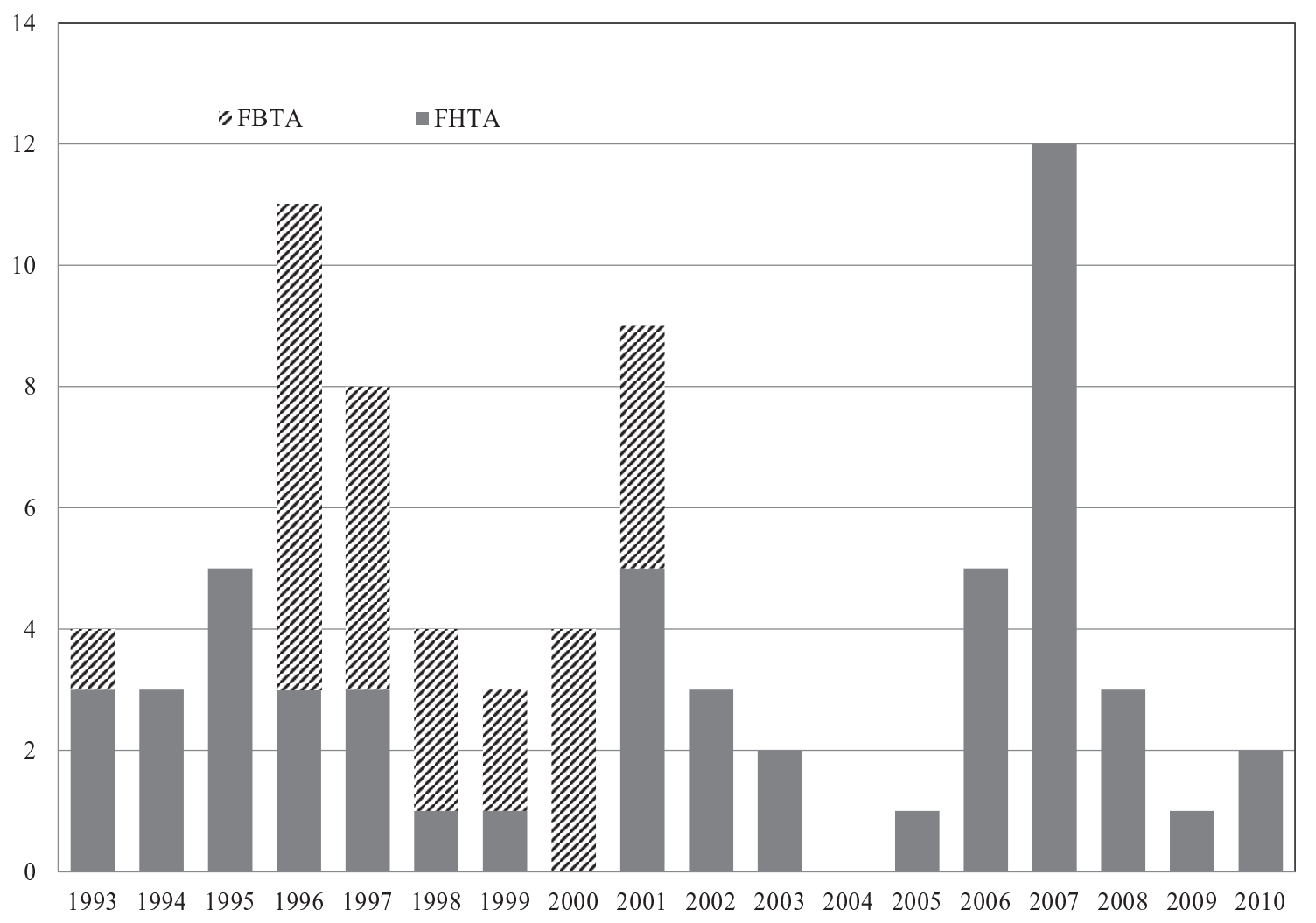

Figure 2: The number of A-share listings by sample firms across the years.

This figure plots the number of A-share listings across the years based on the 80 sample firms that first issued foreign shares and then issued A-shares. The solid bar represents the number of A-share listings by sample firms that first issued H-shares in Hong Kong and then issued A-shares. The dashed bar represents the number of A-share listings by sample firms that first issued B-shares and then A-shares. 
Table 1: Sample distributions.

This table reports the distribution of A-share issuances by first-foreign-then-A sample firms across industries and years. We categorize sample firms according to CSMAR's "INDCD" industry classification and the subperiod of A-shares issuance. Panel A presents the statistics of the full sample, and Panels B and C report the statistics of first-H-then-A firms and first-B-then-A firms, respectively.

\begin{tabular}{|c|c|c|c|c|}
\hline & 1992-1998 & $1999-2004$ & $2005-2010$ & Total \\
\hline \multicolumn{5}{|c|}{ Panel A: Full sample of first-foreign-then-A firms } \\
\hline Finance & - & - & 5 & 5 \\
\hline Utilities & 4 & 7 & 8 & 19 \\
\hline Properties & - & - & 1 & 1 \\
\hline Conglomerates & 3 & 1 & & 4 \\
\hline Industrials & 24 & 13 & 10 & 47 \\
\hline Commerce & 4 & - & & 4 \\
\hline Total & 35 & 21 & 24 & 80 \\
\hline \multicolumn{5}{|c|}{ Panel B: Subsample of first-H-then-A firms } \\
\hline Finance & - & - & 5 & 5 \\
\hline Utilities & 3 & 5 & 8 & 16 \\
\hline Properties & - & - & 1 & 1 \\
\hline Conglomerates & 1 & 1 & - & 2 \\
\hline Industrials & 14 & 5 & 10 & 29 \\
\hline Commerce & - & - & - & - \\
\hline Total & 18 & 11 & 24 & 53 \\
\hline \multicolumn{5}{|c|}{ Panel C: Subsample of first-B-then-A firms } \\
\hline Finance & - & - & - & - \\
\hline Utilities & 1 & 2 & - & 3 \\
\hline Properties & - & - & - & - \\
\hline Conglomerates & 2 & - & - & 2 \\
\hline Industrials & 10 & 8 & - & 18 \\
\hline Commerce & 4 & - & - & 4 \\
\hline Total & 17 & 10 & - & 27 \\
\hline
\end{tabular}


Table 2: Summary statistics of major variables.

This table reports the descriptive statistics of major variables in the A-share listing for first-foreign-thenA firms. Panel A shows the summary statistics, and Panel B reports the correlation coefficients with the Pearson correlation reported in the lower left triangle and the Spearman correlation reported in the upper right triangle. IR $A$ is the A-share underpricing level, calculated by the closing price on the first day of the A-share listing over the offer price and then minus one. $P E \_F$ is the PE of corresponding foreign share observed five days before the A-share listing. PE_Offer is the A-share offer PE reported by the issuer in the offering. Prem_Offer is calculated by the A-share offer price over the corresponding foreign share price five days before the A-share listing and then minus one. Prem_MKT refers to the market-aggregate A-share premium over B- (or H-) share prices, calculated using all cross-listed A-H or A-B shares five-days before the A-share listing. BHRet_F and BHRet_A are the one-year buy-and-hold returns since the second day of A-share listing for foreign and A-shares, respectively. $* * *, * *$, and $*$ denote significance at the $1 \%, 5 \%$, and $10 \%$ levels respectively.

\begin{tabular}{|c|c|c|c|c|c|c|c|}
\hline \multicolumn{8}{|c|}{ Panel A: Summary statistics } \\
\hline & $\mathrm{N}$ & Mean & Std. Error & t-value & Maximum & Median & Minimum \\
\hline IR_A & 80 & $92.77 \%$ & $8.43 \%$ & 11.00 & $348.89 \%$ & $75.72 \%$ & $0.00 \%$ \\
\hline PE_F & 79 & 16.72 & 1.31 & 12.74 & 56.50 & 13.05 & 2.80 \\
\hline PE_Offer & 74 & 22.44 & 1.67 & 13.47 & 97.80 & 18.80 & 3.09 \\
\hline Prem_Offer & 80 & $86.05 \%$ & $15.40 \%$ & 5.59 & $915.49 \%$ & $45.99 \%$ & $-53.43 \%$ \\
\hline Prem_MKT & 77 & $249.35 \%$ & $23.25 \%$ & 10.72 & $1207.09 \%$ & $207.75 \%$ & $-12.41 \%$ \\
\hline BHRet_F & 78 & $28.40 \%$ & $13.14 \%$ & 2.16 & $887.41 \%$ & $14.17 \%$ & $-82.40 \%$ \\
\hline BHRet_A & 78 & $2.67 \%$ & $8.83 \%$ & 0.30 & $439.81 \%$ & $-16.97 \%$ & $-75.32 \%$ \\
\hline \multicolumn{8}{|c|}{ Panel B: Correlation table } \\
\hline & IR_A & PE_F & PE_Offer & Prem_Offer & Prem_MKT & BHRet_F & BHRet_A \\
\hline IR_A & & 0.02 & $-0.24 * *$ & $-0.22 *$ & 0.12 & -0.16 & -0.17 \\
\hline PE_F & -0.02 & & $0.57 * * *$ & $-0.65 * * *$ & $-0.45^{* * *}$ & $-0.22 *$ & -0.11 \\
\hline PE_Offer & -0.18 & $0.69 * * *$ & & -0.09 & $-0.21 *$ & -0.02 & -0.15 \\
\hline Prem_Offer & -0.15 & $-0.40 * * *$ & 0.06 & & $0.64 * * *$ & $0.39 * * *$ & -0.02 \\
\hline Prem_MKT & 0.01 & $-0.28 * *$ & -0.13 & $0.50 * * *$ & & $0.27 * *$ & 0.05 \\
\hline BHRet_F & -0.18 & -0.19 & -0.03 & $0.27 * *$ & 0.11 & & $0.56^{* * *}$ \\
\hline BHRet_A & $-0.26 * *$ & -0.10 & -0.03 & -0.08 & -0.07 & $0.53 * * *$ & \\
\hline
\end{tabular}


Table 3: The informational role of the foreign share price.

This table reports the estimation results of models (17) and (18):

$P E \_A f t 1 m=a_{0}+a_{1} D F B T A+a_{2} T+a_{3} P E \_M K T+a_{4} P E \_F+a_{5} B H R e t_{-} F+a_{6} B H R e t \_A+\varepsilon,(17)$

$P E_{-} O f f e r=b_{0}+b_{1} D F B T A+b_{2} T+b_{3} P E \_M k t+b_{4} P E_{-} F+b_{5} B H R e t \_F+b_{6} B H R e t \_A+\epsilon,(18)$

where $P E \_A f t 1 m$ is the A-share's log PE ratio observed one month after the A-share listing. PE_Offer is the A-share's log offer PE reported by the issuer. DFBTA is a dummy variable, which takes the value of one if the firm first issues B- and then A-shares, and zero if the firm first issues $\mathrm{H}$ - and then $\mathrm{A}-\mathrm{shares}$. $P E \_M K T$ is the market-level PE ratio in the A-share market five days before the A-share listing. $P E \_F$ is the log PE of corresponding foreign share observed five days before the A-share listing. BHRet_F and BHRet_A are the one-year buy-and-hold returns since the second day of the A-share listing for foreign and A-shares, respectively. $T$ takes the value of 1 for A-share IPOs listed in 1992, 2 for 1993, ..., and 19 for 2010. We first estimate models (17) and (18) separately and report the results in columns (1) and (2). The numbers reported in parentheses under the coefficients are t-statistics calculated using White standard errors. ***, **, and $*$ on the coefficients denote significance at the $1 \%, 5 \%$, and $10 \%$ levels, respectively. We then jointly estimate models (17) and (18) by forcing $a_{j}=b_{j}, j=0,, 4$. The Wald statistics are reported for testing the null hypothesis that $a_{4}=b_{4}$ and $a_{5}=b_{5}$. ***, **, and $*$ on the Wald statistics denote one-sided p-value significance at the $1 \%, 5 \%$, and $10 \%$ levels.

\begin{tabular}{|c|c|c|c|c|c|}
\hline & PE_Aft1m & PE_Offer & PE_Aft1m & PE_Offer & Wald \\
\hline & (1) & (2) & (3) & (4) & (5) \\
\hline Intercept & $\begin{array}{l}2.0429 * * * \\
(3.44)\end{array}$ & $\begin{array}{l}1.2646 * \\
(1.77)\end{array}$ & \multicolumn{2}{|c|}{$\begin{array}{c}1.7065 * * * \\
(3.50)\end{array}$} & \\
\hline DFBTA & $\begin{array}{l}0.1076 \\
(0.95)\end{array}$ & $\begin{array}{l}-0.0757 \\
(-0.91)\end{array}$ & \multicolumn{2}{|c|}{-0.0149} & \\
\hline $\mathrm{T}$ & $\begin{array}{l}-0.0089 \\
(-0.46)\end{array}$ & $\begin{array}{l}-0.0158 \\
(-0.67)\end{array}$ & \multicolumn{2}{|c|}{-0.0105} & \\
\hline PE_MKT & $\begin{array}{l}0.0884 \\
(0.58)\end{array}$ & $\begin{array}{l}0.1119 \\
(0.61)\end{array}$ & \multicolumn{2}{|c|}{$\begin{array}{l}0.119 \\
(0.95)\end{array}$} & \\
\hline PE_F & $\begin{array}{l}0.5058^{* * *} \\
(3.63)\end{array}$ & $\begin{array}{l}0.5230 * * * \\
(4.63)\end{array}$ & \multicolumn{2}{|c|}{$\begin{array}{c}0.4562 * * * \\
\quad(4.67)\end{array}$} & \\
\hline BHRet_F & $\begin{array}{l}0.0737 * \\
(1.82)\end{array}$ & $\begin{array}{l}0.0273 \\
(1.00)\end{array}$ & $\begin{array}{l}0.1431^{* *} \\
(2.11)\end{array}$ & $\begin{array}{l}-0.0512 \\
(-0.79)\end{array}$ & $4.65^{* *}$ \\
\hline BHRet_A & $\begin{array}{l}-0.1112 \\
(-1.59)\end{array}$ & $\begin{array}{l}0.0062 \\
(0.12)\end{array}$ & $\begin{array}{l}-0.1401 \\
(-1.35)\end{array}$ & $\begin{array}{l}0.0336 \\
(0.34)\end{array}$ & $1.65^{*}$ \\
\hline$R^{2}$-adjusted & $30.0 \%$ & $35.9 \%$ & & & \\
\hline $\mathrm{N}$ & 75 & 70 & & & \\
\hline
\end{tabular}


Table 4: The anchoring role of the foreign share price: Insufficient adjustment.

This table reports the cross-sectional estimation results of models (19) and (20):

Prem_Offer $=a_{0}+a_{1}$ DFBTA $+a_{2} T+a_{4}$ Prem_MKT $+b_{1}$ BHRet_F $+b_{2}$ BHRet_A $A+\varepsilon,(19)$

$I R \_A=a_{0}+a_{1} D F B T A+a_{2} T+a_{3}$ Prem_Resid $+b_{1} B H R e t \_F+b_{2} B H R e t \_A+c_{1} B H R e t \_F \times$ Dummy $+c_{2} B H R e t \_A \times$ Dummy $+\varepsilon,(20)$

where Prem_Offer is calculated as the A-share offer price over the corresponding foreign share price observed five days before the A-share listing and then minus one. $I R \_A$ is the A-share underpricing level, calculated by the closing price on the first day of the A-share listing over the offer price and then minus one. DFBTA is a dummy variable, which takes the value of one if the firm first issues B- and then A-shares, and zero if the firm first issues $\mathrm{H}$ - and then A-shares. Prem_MKT refers to the market-aggregate A-share premium over B- (or H-) share prices, calculated using all cross-listed A-H or A-B shares five-days before the A-share listing. Prem_Resid is the residual from model (19). BHRet_F and BHRet_A are the one-year buy-and-hold returns since the second day of the A-share listing for foreign and A-shares, respectively. DLarge is a dummy variable, which takes the value of one if the amount of inflationadjusted gross proceeds collected from the A-share issuance is larger than the sample median and zero otherwise. $D \Delta S O$ is a dummy variable, which takes the value of one if the reduction of state ownership in the A-share issuance is greater than the sample median and zero otherwise. DFee is a dummy, which takes the value of one if the flotation cost in the A-share issuance is lower than the sample median and zero otherwise. The dummy $D \sigma_{\theta}^{2}$ takes the value of one when the turnover ratio on the first trading day is higher than the sample median and zero otherwise. $T$ takes the value of 1 for A-share IPOs listed in 1992, 2 for 1993, etc., and 19 for 2010. The numbers reported in parentheses under the coefficients are t-statistics calculated using White standard errors. ***,**, and * denote significance at the $1 \%, 5 \%$, and $10 \%$ levels, respectively.

\begin{tabular}{|c|c|c|c|c|c|c|c|c|}
\hline & \multirow{2}{*}{$\begin{array}{l}\text { Prem_Offer } \\
(1)\end{array}$} & \multicolumn{7}{|c|}{ IR_A } \\
\hline & & (2) & (3) & (4) & (5) & (6) & (7) & (8) \\
\hline Intercept & $\begin{array}{l}0.5177^{*} \\
(1.79)\end{array}$ & $\begin{array}{l}1.1743 * * * \\
(4.15)\end{array}$ & $\begin{array}{l}1.1810 * * * \\
(3.79)\end{array}$ & $\begin{array}{l}1.0329 * * * \\
(3.88)\end{array}$ & $\begin{array}{l}1.0750 * * * \\
(3.53)\end{array}$ & $\begin{array}{l}1.0826^{* * * *} \\
(3.76)\end{array}$ & $\begin{array}{l}1.1951 * * * \\
(4.10)\end{array}$ & $\begin{array}{l}1.0522 * * * \\
(3.80)\end{array}$ \\
\hline DFBTA & $\begin{array}{l}0.1636 \\
(0.64)\end{array}$ & $\begin{array}{l}-0.1896 \\
(-0.92)\end{array}$ & $\begin{array}{l}-0.2108 \\
(-0.98)\end{array}$ & $\begin{array}{l}-0.2301 \\
(-1.18)\end{array}$ & $\begin{array}{l}-0.1695 \\
(-0.77)\end{array}$ & $\begin{array}{l}-0.1840 \\
(-0.89)\end{array}$ & $\begin{array}{l}-0.2306 \\
(-1.10)\end{array}$ & $\begin{array}{l}-0.1594 \\
(-0.83)\end{array}$ \\
\hline $\mathrm{T}$ & $\begin{array}{l}-0.0417 * * \\
(-2.06)\end{array}$ & $\begin{array}{l}-0.0161 \\
(-0.76)\end{array}$ & $\begin{array}{l}-0.0152 \\
(-0.67)\end{array}$ & $\begin{array}{l}-0.0058 \\
(-0.28)\end{array}$ & $\begin{array}{l}-0.0091 \\
(-0.40)\end{array}$ & $\begin{array}{l}-0.0118 \\
(-0.54)\end{array}$ & $\begin{array}{l}-0.0156 \\
(-0.73)\end{array}$ & $\begin{array}{l}-0.0107 \\
(-0.50)\end{array}$ \\
\hline Prem_MKT & $\begin{array}{l}0.2043^{* * * *} \\
(4.10)\end{array}$ & & & & & & & \\
\hline Prem_Resid & & & $\begin{array}{l}-0.1862 \\
(-1.49)\end{array}$ & $\begin{array}{l}-0.2029^{*} \\
(-1.81)\end{array}$ & $\begin{array}{l}-0.2235 * * \\
(-2.08)\end{array}$ & $\begin{array}{l}-0.2233^{*} \\
(-1.79)\end{array}$ & $\begin{array}{l}-0.1878 \\
(-1.44)\end{array}$ & $\begin{array}{l}-0.2091 * \\
(-1.78)\end{array}$ \\
\hline BHRet_F & $\begin{array}{l}0.2606 * * * \\
(2.70)\end{array}$ & $\begin{array}{l}-0.0303 \\
(-0.41)\end{array}$ & $\begin{array}{l}-0.0181 \\
(-0.29)\end{array}$ & $\begin{array}{l}0.3202 * * \\
(2.36)\end{array}$ & $\begin{array}{l}0.1455 \\
(1.06)\end{array}$ & $\begin{array}{l}0.2918^{*} \\
(1.77)\end{array}$ & $\begin{array}{l}-0.1594 \\
(-1.14)\end{array}$ & $\begin{array}{l}0.3452^{*} \\
(1.87)\end{array}$ \\
\hline BHRet_A & $\begin{array}{l}-0.2253 \\
(-1.57)\end{array}$ & $\begin{array}{l}-0.2101 * * * \\
(-2.88)\end{array}$ & $\begin{array}{l}-0.2286^{* * *} \\
(-2.86)\end{array}$ & $\begin{array}{l}-1.3272^{* * *} \\
(-3.08)\end{array}$ & $\begin{array}{l}-0.8020^{*} \\
(-1.90)\end{array}$ & $\begin{array}{l}-1.3134 * * \\
(-2.41)\end{array}$ & $\begin{array}{l}-0.0582 \\
(-0.59)\end{array}$ & $\begin{array}{l}-2.1082^{* * * *} \\
(-3.81)\end{array}$ \\
\hline BHRet_F $\times$ DLarge & & & & $\begin{array}{l}-0.5033 * * \\
(-2.58)\end{array}$ & & & & $\begin{array}{l}-0.7054 \\
(-1.51)\end{array}$ \\
\hline BHRet_A $\times$ DLarge & & & & $\begin{array}{l}1.2548^{* * * *} \\
(2.89)\end{array}$ & & & & $\begin{array}{l}1.2059^{* *} \\
(2.43)\end{array}$ \\
\hline BHRet_F $\times$ D $\Delta$ SO & & & & & $\begin{array}{l}-0.2160 \\
(-0.96)\end{array}$ & & & $\begin{array}{l}0.1002 \\
(0.37)\end{array}$ \\
\hline BHRet_A $\times \mathrm{D} \Delta \mathrm{SO}$ & & & & & $\begin{array}{l}0.6472 \\
(1.51)\end{array}$ & & & $\begin{array}{l}0.2273 \\
(0.64)\end{array}$ \\
\hline BHRet_F $\times$ DFee & & & & & & $\begin{array}{l}-0.5164 * * \\
(-2.35)\end{array}$ & & $\begin{array}{l}0.0410 \\
(0.10)\end{array}$ \\
\hline BHRet_A $\times$ DFee & & & & & & $\begin{array}{l}1.2414^{* * *} \\
(2.27)\end{array}$ & & $\begin{array}{l}0.6924 \\
(1.18)\end{array}$ \\
\hline BHRet_F $\times \mathrm{D} \sigma_{\theta}^{2}$ & & & & & & & $\begin{array}{l}0.2764 * \\
(1.85)\end{array}$ & $\begin{array}{l}0.2690^{*} \\
(1.72)\end{array}$ \\
\hline BHRet_A $\times$ D $\sigma_{\theta}^{2}$ & & & & & & & $\begin{array}{l}-0.5297 * \\
(-1.79)\end{array}$ & $\begin{array}{l}-0.2109 \\
(-1.22)\end{array}$ \\
\hline$R^{2}$-adjusted & $35.0 \%$ & $3.6 \%$ & $6.3 \%$ & $16.6 \%$ & $6.6 \%$ & $16.0 \%$ & $7.9 \%$ & $20.8 \%$ \\
\hline $\mathrm{N}$ & 75 & 78 & 75 & 75 & 75 & 71 & 74 & 70 \\
\hline
\end{tabular}




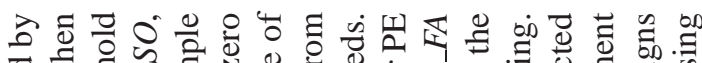

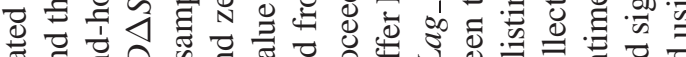
零

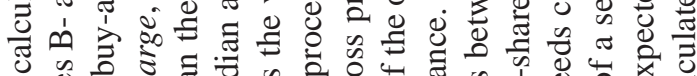

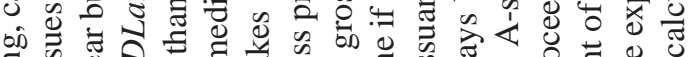


눈

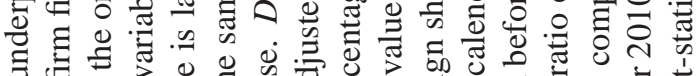

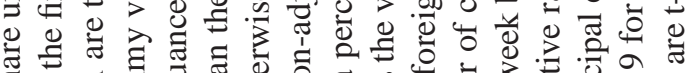

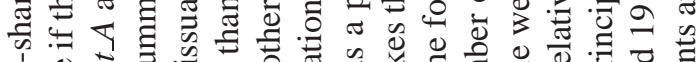



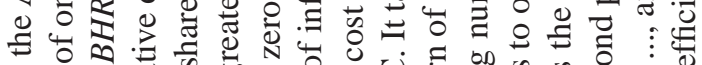

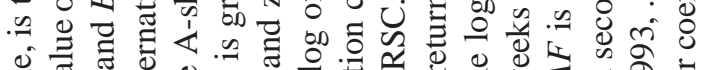

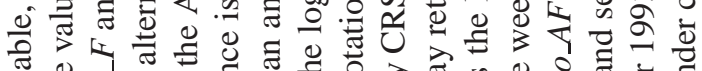

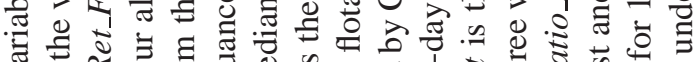

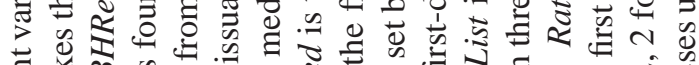

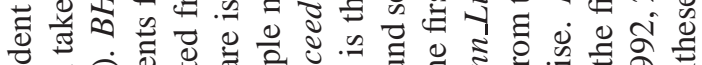

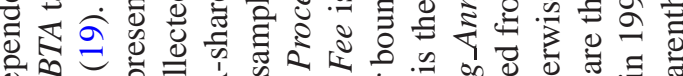

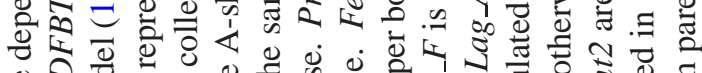

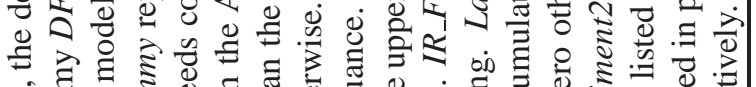

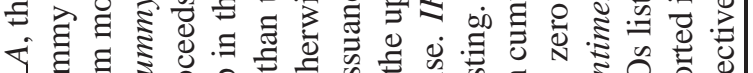

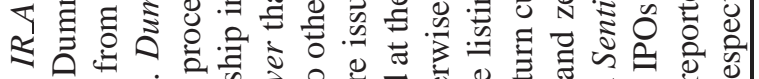

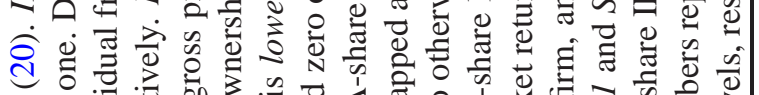

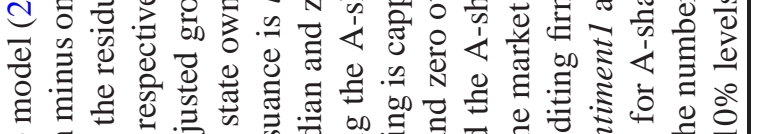
可. 记

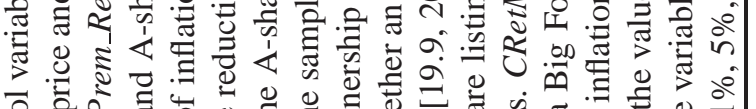

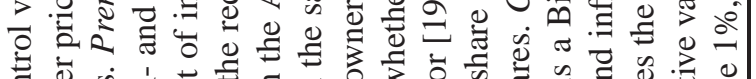

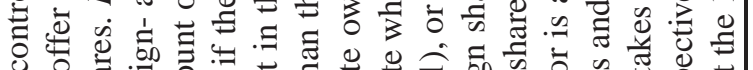

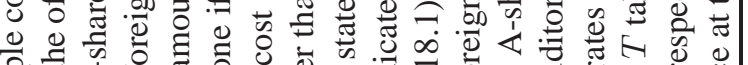

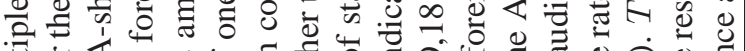

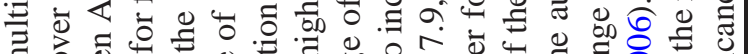



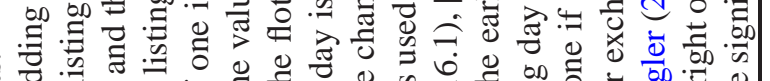

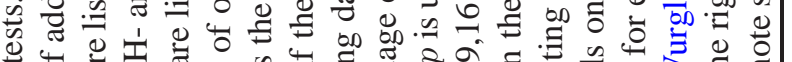

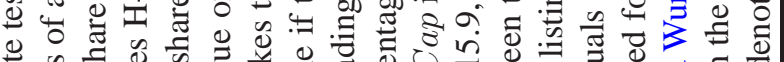

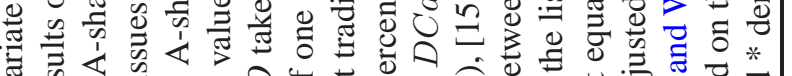

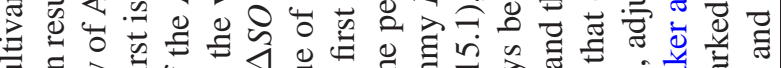

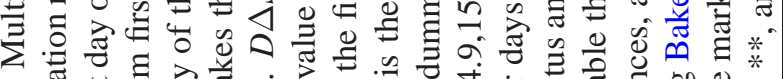

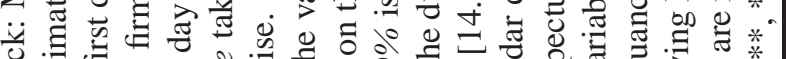

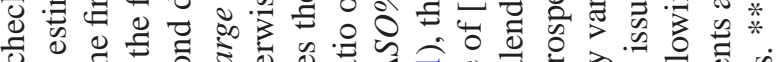

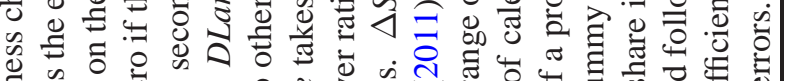

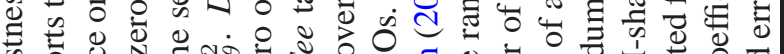

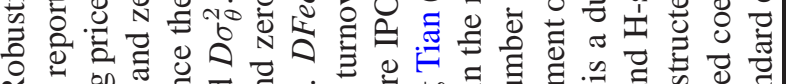

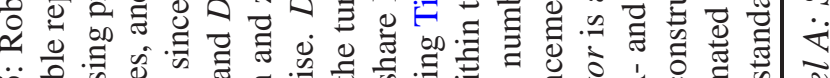

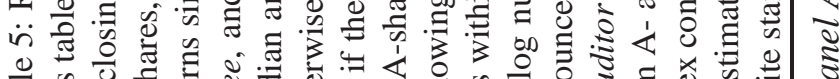

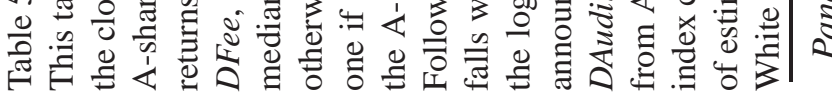

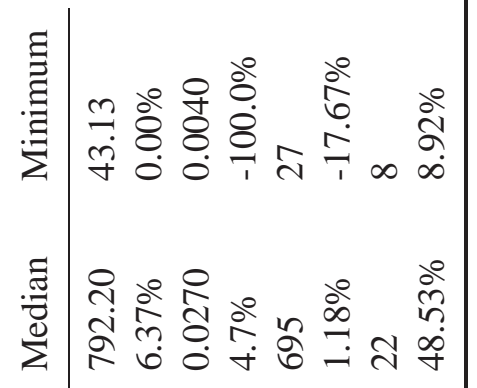

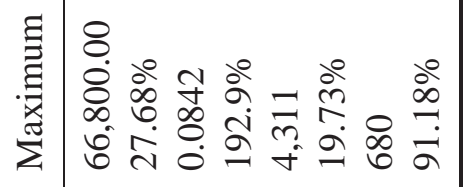

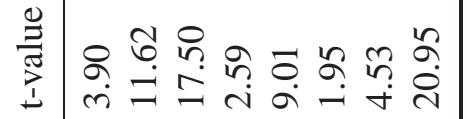

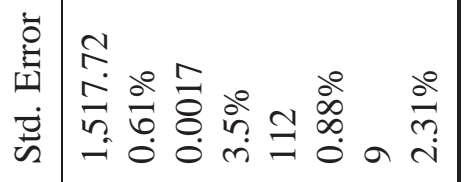

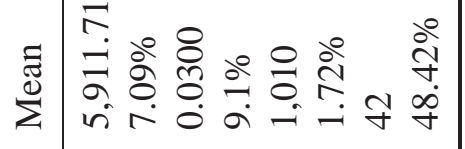

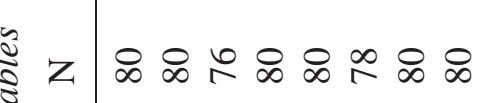

.

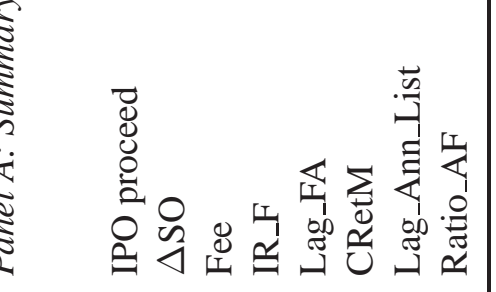




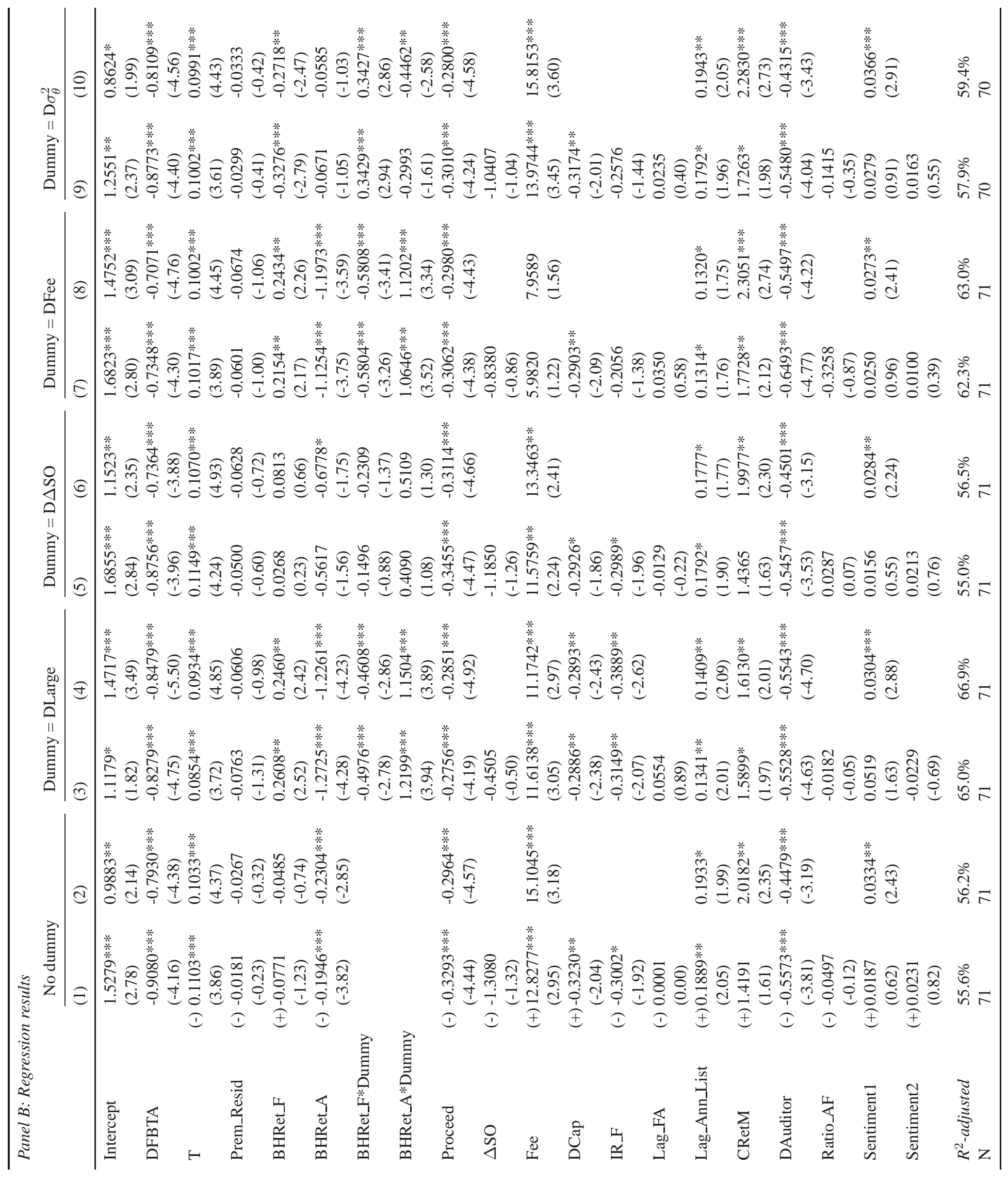




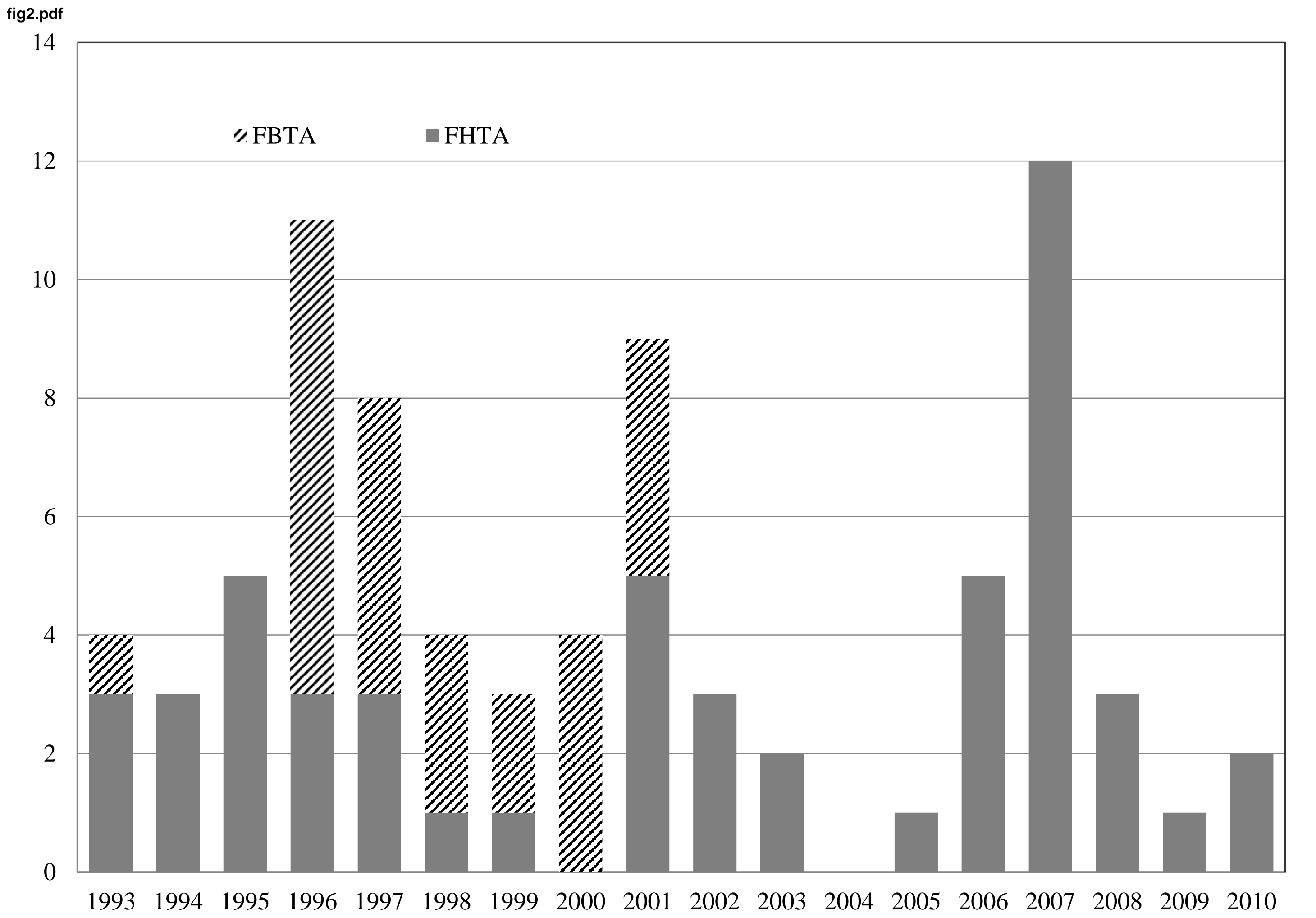

